Document downloaded from:

http://hdl.handle.net/10251/165715

This paper must be cited as:

Schwanke, AJ.; Balzer, R.; Lopes, CW.; Meira, DM.; Díaz Morales, UM.; Corma Canós, A.; Pergher, S. (2020). A Lamellar MWW Zeolite With Silicon and Niobium Oxide Pillars: A Catalyst for the Oxidation of Volatile Organic Compounds. Chemistry - A European Journal. 26(46):1-12. https://doi.org/10.1002/chem.202000862

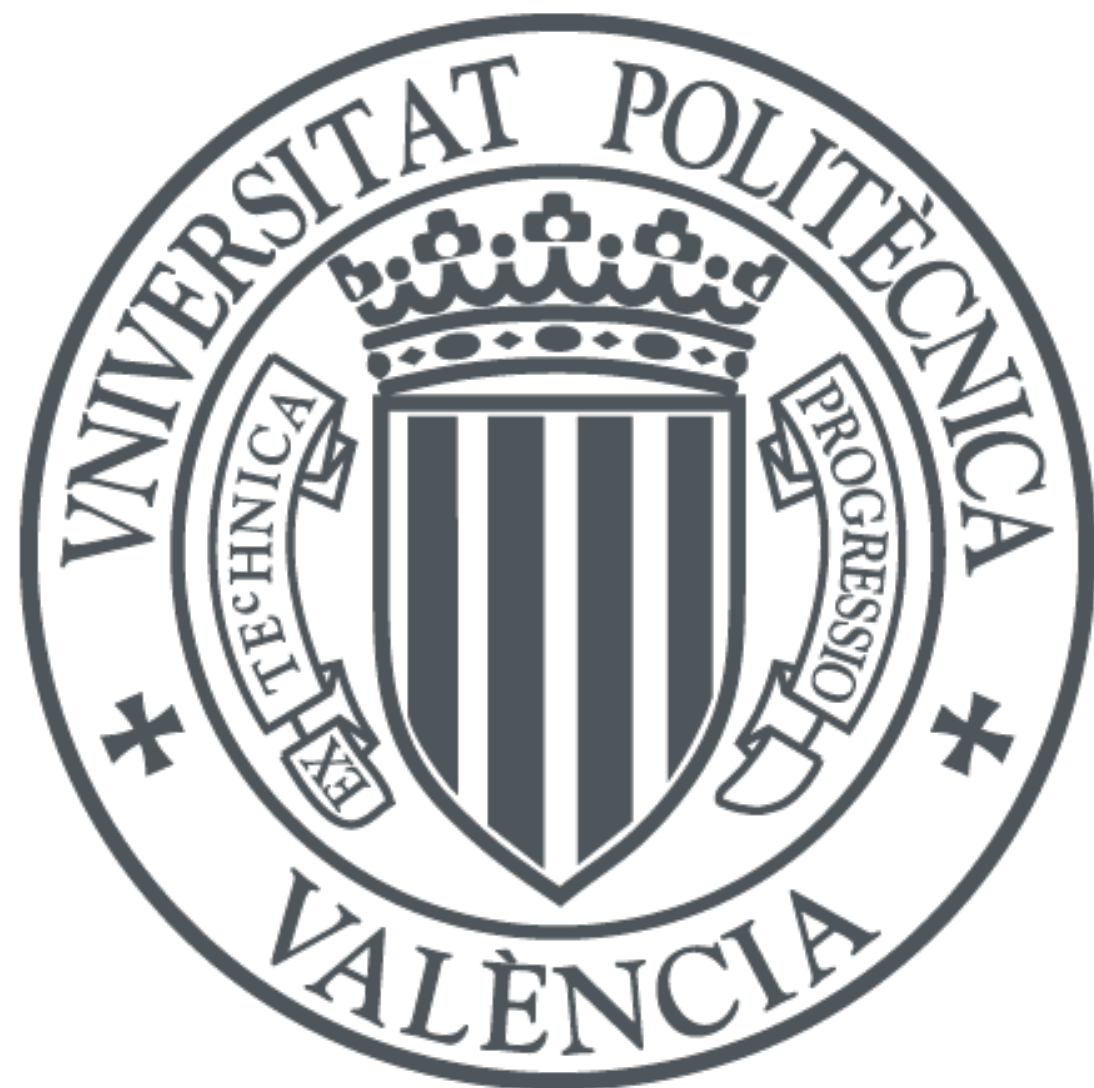

The final publication is available at

https://doi.org/10.1002/chem.202000862

Copyright John Wiley \& Sons

Additional Information

This is the peer reviewed version of the following article: A. J. Schwanke, R. Balzer, C. Wittee Lopes, D. Motta Meira, U. Díaz, A. Corma, S. Pergher, Chem. Eur. J. 2020, 26, 10459, which has been published in final form at https://doi.org/10.1002/chem.202000862. This article may be used for non-commercial purposes in accordance with Wiley Terms and Conditions for Self-Archiving. 


\title{
Lamellar MWW zeolite with silicon and niobium oxide pillars - A catalyst for the oxidation of volatile organic compounds
}

\author{
Anderson Joel Schwanke ${ }^{\mathrm{a}}$, Rosana Balzer ${ }^{\mathrm{b}}$, Christian Wittee Lopes ${ }^{\mathrm{a}}$, Débora Motta \\ Meira $^{\mathrm{c}}$, Urbano Díaz ${ }^{\mathrm{d}}$, Avelino Corma ${ }^{\mathrm{d}}$, Sibele Pergher ${ }^{\mathrm{e}}$ \\ ${ }^{\text {a }}$ Universidade Federal do Rio Grande do Sul, 91501-970, Porto Alegre, RS, Brasil. \\ *Corresponding author: anderson-js@live.com \\ ${ }^{\text {b }}$ Universidade Federal do Paraná - UFPR, 85950-000, Palotina, PR, Brasil. \\ ${ }^{\mathrm{c}}$ Argonne National Laboratory, 9700 S. Cass Avenue, Argonne, IL 60439, United States. \\ d Instituto de Tecnología Química, 4602, Valencia, España. \\ ${ }^{\mathrm{e}}$ Universidade Federal do Rio Grande do Norte, 59078-970, Natal, RN, Brasil.
}

\begin{abstract}
In this work, an MWW-type zeolite with pillars containing silicon and niobium oxide was synthesized to obtain a hierarchical zeolite. The effect of niobium insertion in the pillaring process was determined by combining a controllable acidity and accessibility in the final material. All pillared materials had niobium occupying framework positions in pillars and extra-framework positions. The pillared material, Pil-Nb-4.5 with $4.5 \mathrm{wt} \%$ niobium, did not compromise the mesoporosity formed by pillaring, while the increase of niobium in the structure gradually decreased the mesoporosity and ordering of lamellar stacking. The morphology of the pillared zeolites and the niobium content were found to directly affect the catalytic activity. Specifically, we report on the activity of the MWW-type zeolites with niobium catalyzing the gas-phase oxidation of volatile organic compounds (VOCs), which is an important reaction for clean environmental. All produced MWW-type zeolites with niobium were catalytically active, even at low temperatures and low niobium loading, and provided excellent conversion efficiencies.
\end{abstract}




\section{INTRODUCTION}

Catalysis is directly related with the development of materials with catalytically active sites that selectively drive target transformations with high performance under soft and environmentally friendly conditions. ${ }^{[1]}$ Niobium (Nb)-based structures have been extensively employed in catalysis and electrocatalysis applications. ${ }^{[2]}$ There is a crescent attempt related to use of $\mathrm{Nb}$ as a promoter, catalytically active phase or support in the process of catalyst preparation. ${ }^{[3]}$ An understanding of the energetics, spectroscopic properties and molecular structures of supported niobium catalysts has permitted the prediction of the optimal composition and structure of catalysts for specific catalytic processes. ${ }^{[4]}$ However, for practical purposes, the identification and optimization of active sites are challenging because chemical reactions often occur at poorly defined solid-gas or solid-liquid interfaces. ${ }^{[5]}$ The synthesis strategies to obtain niobium-containing mesoporous silica and other molecular sieves has systematically increased over time as well as the understading of their physicohemical properties. ${ }^{[3]}$ Hierarchical zeolites have received substantial attention in recent years. This strategy emerged from the necessity to combine accessibility and catalytic activity that is higher than that in typical ordered mesoporous materials, i.e., M41S and SBA-15. ${ }^{[6]}$

In the category of hierarchical zeolites, pillared zeolites belong to a "bottom-up" approach, where the procedure involves separating and establishing pillars between MWW zeolitic lamellae. ${ }^{[7]}$ Moreover, pillared zeolites offer adjustable properties as high surface area and sorption capacities, mesoporous dimensions obtained from the control of the length of pillars and tuneable hydrophobicity/hydrophilicity. ${ }^{[8]}$ Consequently, the first pillared zeolite structure was called MCM-36, ${ }^{[9]}$ and was obtained from the expansion of a lamellar zeolitic precursor with MWW topology known as MCM-22P. ${ }^{[10]}$ The lamellar zeolitic precursor was intercalated with surfactants followed by further addition of a pillaring agent-based silicon alkoxide, which after calcination, formed rigid $\mathrm{SiO}_{2}$ pillars between the lamellae. MCM-36 present remarkable performance as catalyst for vacuum gas oil cracking and alkylation and support for enzymes. ${ }^{[9,11]}$ Subsequently, the stabilization of $\mathrm{SiO}_{2}$ pillars was extended to other lamellar zeolites including TiMCM-36 titanosilicates, ITQ-36 (FER), pillared MCM-39 (NSI), pillared MFI nanosheets, pillared ilerite (RWR), pillared IPC-1P and Ti-IPC-1PISi (UTL). ${ }^{[12]}$

In contrast, $\mathrm{SiO}_{2}$ pillars are also considered as inert space fillers and associated with partial blockage of active sites present between the external surfaces of lamellae. ${ }^{[13]}$ A way to compensate this blockage involve inserting active species in the pillars, which 
could be combined with the accessibility of the formed galleries. However, studies focused in lamellar zeolites which the pillars play a role as active species are scarce and still a real opportunity for advanced studies on pillared zeolites. ${ }^{[14]}$ MCM-36 with alumina-magnesia as mixed pillars was the first example of this approach and had pore diameters of 2-4 $\mathrm{nm}$, and this concept was extended to other mixed pillars with $\mathrm{BaO}-$ $\mathrm{Al}_{2} \mathrm{O}_{3}, \mathrm{Al}_{2} \mathrm{O}_{3}-\mathrm{SiO}_{2}, \mathrm{MgO}-\mathrm{Al}_{2} \mathrm{O}_{3}-\mathrm{SiO}_{2}$, and $\mathrm{BaO}-\mathrm{Al}_{2} \mathrm{O} 3-\mathrm{SiO}_{2} \cdot{ }^{[15]}$ A pillared $\mathrm{MWW}$ zeolite with $\mathrm{Si} / \mathrm{Ti}$ as mixed pillars was reported as catalysts for epoxidation of cyclooctene. ${ }^{[16]}$ Recently, a pillared MWW with niobiosilicate was reported, and the materials were active for cyclohexene oxidation and methylene blue discoloration with hydrogen peroxide. ${ }^{[17]}$ Other successful example of zeolite with pillars as active species include TS-1 (MFI) with Si/Ti pillars applied for epoxidation of cyclooctene, norbornene and $\alpha$-pinene, ${ }^{[18]}$ and TiIPC-1PITi (UTL) with Si/Ti pillars applied for epoxidation of cyclooctene, norbornene, and linalool. ${ }^{[12 \mathrm{~g}]}$

In fact, niobium oxide proved to be a versatile catalyst for several reactions, e.g., oxidation, esterification, dehydration, dehydrogenation, hydrogenation, photocatalysis and other applications, such as enzyme immobilization and chemical sensing. ${ }^{[4 a, 5,19]}$ Additionally, the interest to prepare niobium-containing microporous and mesoporous materials, such as MFI, FAU, BEA, AlPOs, SBA-3, MCM-41, SBA-15, KIT-5, and a layered niobium oxide, is still growing. ${ }^{[20]}$ Here, we prepared a lamellar MWW-type zeolite with silicon and niobium oxide as pillars where the catalytic performance can be optimized by careful control of physicochemical properties.

We focused on the catalytic gas-phase oxidation of toxic volatile organic compounds (VOCs), which represents an important transformation for environmental remediation and where enhanced catalytic performance could provide improved degradation efficiencies with decreased energy costs. ${ }^{[21]}$ Catalytic oxidation has been recognized as the most effective approach, mainly due to its high degradation efficiency, low energy cost, and the potential for the removal VOCs in low concentrations. ${ }^{[22]} \mathrm{We}$ demonstrate that the physicochemical properties of MWW-type zeolite with pillars of silicon and niobium oxide have a strong impact on the gas-phase oxidation activity of VOCs.

\section{EXPERIMENTAL}

2.1 Synthesis of MCM-22 and its precursor: In a plastic beaker containing $9.0 \mathrm{~mol}$ of distilled water, it was added $18.5 \mathrm{mmol}$ of sodium hydroxide $(\mathrm{NaOH}$, Sigma 
Aldrich) kept in stirring during $10 \mathrm{~min}$. Then, it was added $9.0 \mathrm{mmol}$ of sodium aluminate $\left(\mathrm{NaAlO}_{3}\right.$, Riedel-de-Haën) under continuous stirring until its complete dissolution. Then, $0.1 \mathrm{~mol}$ of the organic structure directing agent, hexamethyleneimine (HMI, Sigma Aldrich), was added and followed by the addition of $0.2 \mathrm{~mol}$ of silica (Aerosil 200, Degussa). After $2 \mathrm{~h}$ of continuous stirring, the mixture was placed in a autoclaves containing PFTE recipes and kept in an oven at $135{ }^{\circ} \mathrm{C}$ with a system of rotation of the autoclaves during 7 days. Afterwards, the material was filtered with distilled water, dried and stored in a plastic flask. The precursor $(\mathrm{P})$ was calcined for 12 h at $580{ }^{\circ} \mathrm{C}$ to eliminate the HMI and to obtain the MCM-22

2.2 Swelling precursor: The material was obtained with a mixture kept for 18 $\mathrm{h}$ in stirring at room temperature, $25^{\circ} \mathrm{C}$. The mixture was done with $4.8 \mathrm{~g}$ of distilled water, $1.2 \mathrm{~g}$ of MCM-22 precursor and $12.0 \mathrm{~g}$ of a $29 \mathrm{wt} \%$ hexadecyltrimethylammonium bromide $\left(\mathrm{C}_{16} \mathrm{TABr}\right.$, 98\%, Sigma Aldirch) solution previously exchanged by $\mathrm{OH}^{-}$ions with an ionic exchange resing (Dowex). The material was washed several times until $\mathrm{pH}=9$ and labeled as $\operatorname{Swollen}(\mathrm{P})$.

2.3 Pillaring: The procedure was done similar to the literature. ${ }^{[12 \mathrm{~g}, 18]}$ It was used $\mathrm{N}_{2}$ atmosphere and a reflux condensed system during $24 \mathrm{~h}$ at $80^{\circ} \mathrm{C}$. The Swollen(P) material was added with tetraethyl orthosilicate (TEOS, Sigma Aldrich) with a 1:5 wt/wt ratio and niobium ethoxide (99.9\%, Sigma Aldrich) with $\mathrm{Si} / \mathrm{Nb}$ molar ratios $=50,25$, 15,10 . The resulting materials were hydrolyzed with water during $12 \mathrm{~h}$ at $40{ }^{\circ} \mathrm{C}$ and dried. To eliminate the organic content, a calcination was done using a vertical tubular reactor with a ramp of $0.05{ }^{\circ} \mathrm{C} \mathrm{s}^{-1}$ up to $550{ }^{\circ} \mathrm{C}\left(\mathrm{N}_{2}\right.$ flowing) kept at the same temperature for additional $8 \mathrm{~h}\left(\mathrm{O}_{2}\right.$ flowing $)$. The $\mathrm{Nb}$-containing pillared $\mathrm{MWW}$-type materials were labeled as Pil-Nb-x, where $x$ is the $\mathrm{Nb}$ percentage $(\%)$ determined by ICP. Niobium oxide (99.9\%, Alfa Aesar) was used as a reference.

2.4 Oxidation of VOCs: The conditions were: $30 \mathrm{mg}$ catalyst; benzene ( $1.3 \mathrm{~g}$ $\left.\mathrm{m}^{-3}\right)$, toluene $\left(0.7 \mathrm{~g} \mathrm{~m}^{-3}\right)$, and o-xylene $\left(0.6 \mathrm{~g} \mathrm{~m}^{-3}\right)$ added to air; gas flow rate of $20 \mathrm{~cm}^{3}$ $\min ^{-1}$; residence time of $0.3 \mathrm{~s}$; space velocity of $12000 \mathrm{~mL} \cdot \mathrm{g}^{-1} \mathrm{~h}^{-1}$; and temperature range of between 50 and $300{ }^{\circ} \mathrm{C}$. It was used quartz reactor under atmospheric pressure. The data were collected after $2 \mathrm{~h}$ on-stream at room temperature and the products were determined with a GC-MS. The subtract and product mixtures were analyzed using two online gas chromatographs. The conversion of BTX follows:

$$
\text { Conv. (\%): } \frac{\text { Xinput-Xoutput }}{\text { Xinput }} .100
$$

Where $X$ represents the benzene, toluene or o-xylene. 
2.5 Characterization: The elemental analyses of silicon, aluminium and niobium were recorded with a 715-ES (Varian, ICP). The morphology of samples was analysed on a Ultra 55 at $2 \mathrm{kV}$ (ZEISS, FESEM). TEM images were collected JEM 2100F (JEOL, $200 \mathrm{kV}$ ) using high-angle annular dark-field (HAADF) and bright field (BF) and modes. The crystalline structure of solids were measured on diffractometer Cubix (PANalytical) using copper K-alpha radiation. The textural properties were collected with a $\mathrm{N}_{2}$ and Ar sortometer ASAP 2010 and ASAP 2020 (Micromeritics), respectively, outgassing the samples at $300{ }^{\circ} \mathrm{C}$ for $12 \mathrm{~h}$ before the measurements. The Brunnauer, Emmet and Teller method was used to calculate the specific surface area. Infrared spectroscopy with adsorption-desorption of pyridine as proble molecule was performed in a Nicolet 710 (Thermo Fisher Scientific) and the absorption coefficients were calculated according to Emeis method. ${ }^{[23]}$ Diffuse reflectance UV-Vis spectroscopy was collected on a Cary 5000 (1.12, Varian). The experiments of X-ray photoelectron spectroscopy (XPS) were carried out in an Omicron-SPHERA station. Xray Absorption Spectroscopy experiments were carried out at $\mathrm{Nb} \mathrm{K}$-edge $(18986 \mathrm{eV})$ at the 20 BM beamline of Argonne National Laboratory (Lemont, IL, USA). The samples were pelletized (pellets of an optimized thickness) and the spectra were collected in transmission mode by means of ionization chambers. Energy calibration was checked by $\mathrm{Nb}$ foil placed between $\mathrm{I}_{1}$ and $\mathrm{I}_{2}$ ionization chambers. Reference compounds were also measured in order to have a proper comparison with the measured samples. In order to ensure spectral reproducibility and a good signal-to-noise ratio, three scans were acquired at each measurement step. Data treatment have been performed using the IFEFFIT-based package ${ }^{[24]}$.

\section{RESULTS AND DISCUSSION}

The diffratograms of all solids obtained are shown in Figure 1. For the precursor MCM-22(P), the diffraction peaks located at $2 \theta=3.3^{\circ}$ and $6.6^{\circ}$ are related with the $(001)$ and (002) reflections of the MWW zeolitic lamellar stacks, where the individual lamella have a $2.5 \mathrm{~nm}$ thickness. ${ }^{[25]}$ The $\mathrm{d}_{001}$ spacing of the MCM-22(P) with $2.6 \mathrm{~nm}$ corresponds to the sum of the thickness of a MWW lamellae and the $0.1 \mathrm{~nm}$ thickness of the silanol groups located on the upper and lower surface of each lamella. After calcination, silanol 
groups between the lamellae are condensed, and HMI is removed for the formation of the tridimensional MCM-22 zeolite.

The swollen precursor shows an increase in the $\mathrm{d}_{001}$ spacing, where the peak position shifted to $2 \theta=2.2^{\circ}(4.0 \mathrm{~nm})$ due to surfactant molecules accommodated between the MWW lamellae. This finding is confirmed by the widening of (101) and (102) peaks due to loss of the ordering of the stacked lamellae along the $c$ axis.

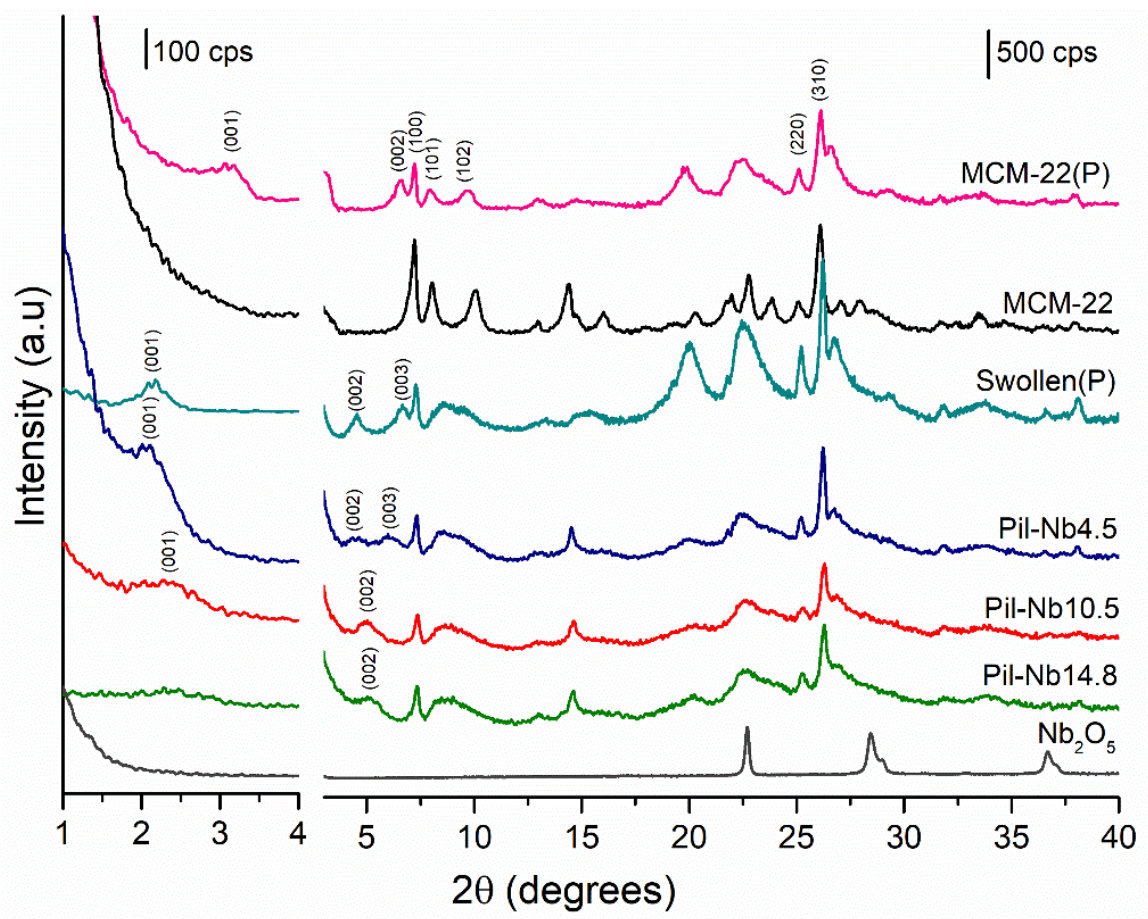

Figure 1. Diffractograms of MCM-22(P), Swollen(P), MCM-22, Pil-Nb-4.5, Pil-Nb10.5 and Pil-Nb-14.8.

The introduction of niobium and silicon as oxide pillars maintains the separation of the individual MWW lamellae, which is observed by the union of the (101) and (102) diffraction peaks to form a broad peak due to the loss of vertical arrangement of the lamellae along the $c$ axis in all pillared materials. For the Pil-Nb-4.5 material, it is observed that the $(00 l)$ diffraction peaks are maintained after calcination with a widening of the $(00 l)$ peaks, an increase in the $\mathrm{d}_{001}$ to $4.0 \mathrm{~nm}$. The XRD patterns of the Pil-Nb-10.5 and Pil-Nb-14.8 materials show a decrease in the $\mathrm{d}_{001}$ spacing to $3.6 \mathrm{~nm}$. Moreover, a gradual decrease in the order of the lamellar stacking with an increase in the niobium content observed by the widening of the $(00 l)$ diffraction band are attributed to the increase in the geometry distortions in pillars. In addition, it is observed that the pillars do not collapse for the Pil-Nb-14.8 material since the broad peak in the region between $2 \theta=8-10^{\circ}$ is maintained as well as the broad (002) peak at $2 \theta=5.1^{\circ}$, which is located at a lower angle than the MCM-22(P) (002) peak at $2 \theta=6.6^{\circ}$. 
Regarding the niobium speciation, it is well known that the sensitivity of XRD requires greater than $5 \%$ of crystalline phases to be present, and part of the $\mathrm{Nb}$ might be in the oxide form occupying extra-framework positions. ${ }^{[20 \mathrm{~b}]}$ Another possibility lays in the formation of an amorphous niobium oxide phase, which is not detected by XRD. In our case, no crystalline phases of $\mathrm{Nb}$ oxide are present even in pillared samples with a high $\mathrm{Nb}$ content, i.e., $14.8 \%$ (Pil-Nb-14.8). This was confirmed by the absence of crystalline $\mathrm{Nb}$ oxide XRD diffraction peaks at $2 \theta=22.6,28.3$ and $36.6^{\circ}$, which are shown as a reference in Figure 1. The $\mathrm{Nb}$ local environment will be addressed further.

Table 1 shows the chemical composition of the samples. The Swollen(P) had a $\mathrm{Si} / \mathrm{Al}$ molar ratio $=18$, which is less than the MCM-22 ratio of $\mathrm{Si} / \mathrm{Al}=22$. This decrease is due to the partial desilication of the MCM-22(P) during the swelling procedure with an alkaline media. On the other hand, the pillared samples Pil-Nb-4.5, Pil-Nb-10.5 and Pil$\mathrm{Nb}-14.8$ and have an increase in the $\mathrm{Si} / \mathrm{Al}$ ratio of 28, 36 and 32, respectively, confirming that materials contain more silicon due to the pillars.

Table 1. Composition and textural properties of MCM-22, Pil-Nb-4.5, Pil-Nb-10.5, Pil$\mathrm{Nb}-14.8$ and Pil-Nb-24 materials.

\begin{tabular}{cccccccc}
\hline Sample & $\begin{array}{c}\text { Si/Nb } \\
\text { (ICP) }\end{array}$ & $\begin{array}{c}\text { Si/Al } \\
(\text { ICP })\end{array}$ & $\begin{array}{c}\mathbf{S}_{\text {BET }} \\
\left(\mathrm{m}^{2} \mathrm{~g}^{-1}\right)\end{array}$ & $\begin{array}{c}\mathbf{S}_{\text {ext }} \\
\left(\mathrm{m}^{2} \mathrm{~g}^{-1}\right)\end{array}$ & $\begin{array}{c}\mathbf{V}_{\text {TP }} \\
\left(\mathrm{cm}^{3} \mathrm{~g}^{-1}\right)\end{array}$ & $\begin{array}{c}\mathbf{V}_{\text {micro }} \\
\left(\mathrm{cm}^{3} \mathrm{~g}^{-1}\right)\end{array}$ & $\begin{array}{c}\mathbf{V}_{\text {meso }} \\
\left(\mathrm{cm}^{3} \mathrm{~g}^{-1}\right)\end{array}$ \\
\hline MCM-22 & -- & 22 & 450 & 120 & 0.64 & 0.15 & 0.09 \\
Pil-Nb-4.5 & 60 & 28 & 833 & 727 & 0.90 & 0.03 & 0.33 \\
Pil-Nb-10.5 & 35 & 36 & 711 & 373 & 0.46 & 0.15 & 0.09 \\
Pil-Nb-14.8 & 19 & 32 & 614 & 331 & 0.42 & 0.14 & 0.08 \\
\hline
\end{tabular}

The $\mathrm{N}_{2}$ a isotherms of the pillared samples are shown in Figure 2a. The Pil-Nb4.5 material shows steep adsorption between 0.12 and 0.4 of the $p / p^{0}$ region that was created by pillaring and is due to capillary condensation occurring in the mesopores. For the other pillared materials, the $\mathrm{N}_{2}$ adsorption at low pressures is mainly due to the presence of micropores, while the MCM-22 zeolite possesses a type I isotherm typical of materials with micropores. ${ }^{[26]}$

The pore size distribution of the MWW-type materials presented in Figure $2 b$ shows pore widths $\left(\mathrm{W}_{\mathrm{p}}\right)$ ranging between 2 - $4 \mathrm{~nm}$ (small mesopores) in the case of Pil$\mathrm{Nb}-4.5$. The decreasing $\mathrm{W}_{\mathrm{p}}$ to the range of supermicropores was observed for the pillared samples with high $\mathrm{Nb}$ content, Pil-Nb-4.5 and Pil-Nb-10.5. In the specific case of Pil-Nb- 
14.8, the MWW lamellae did not collapse when their $\mathrm{W}_{\mathrm{p}}$ profiles are compared with those of the MCM-22 zeolite. These results are consistent with the XRD results that were previously discussed.
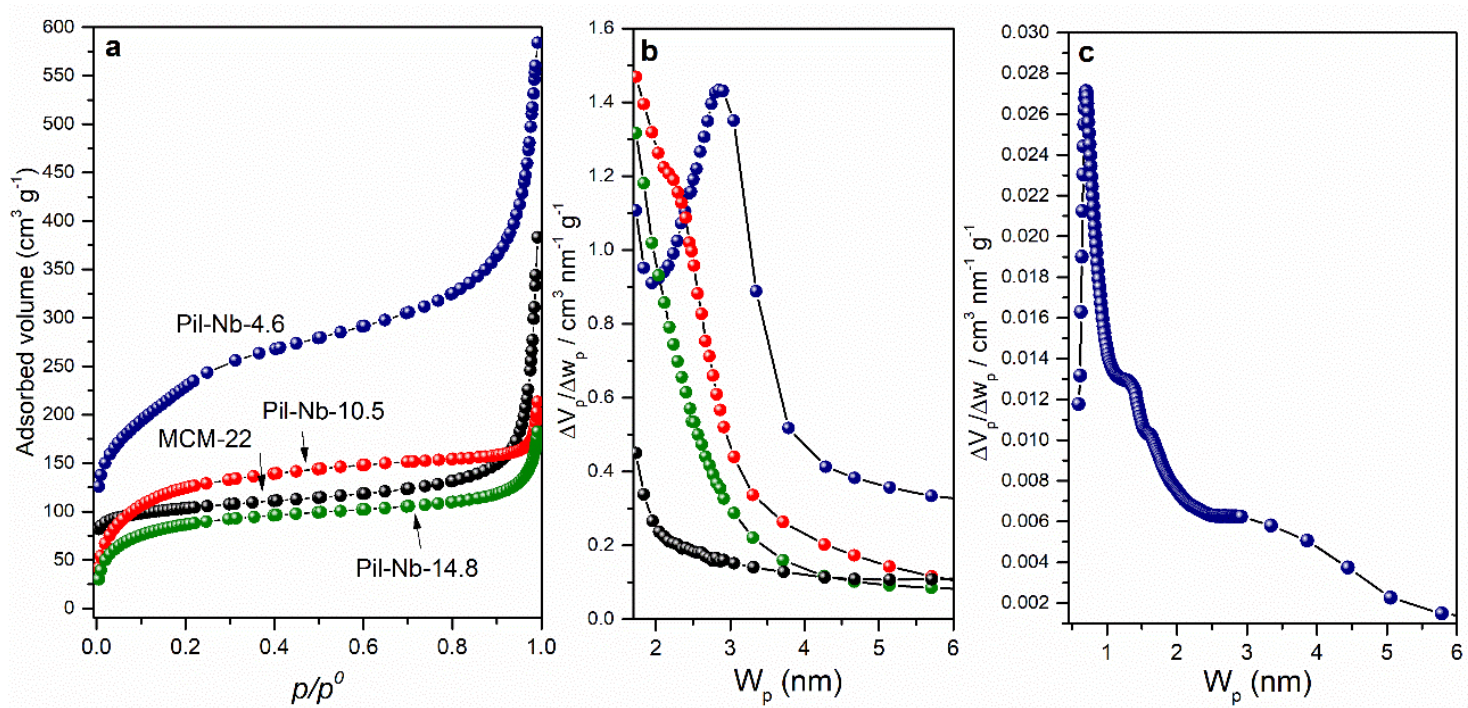

Figure 2. (a) $\mathrm{N}_{2}$ adsorption isotherms and (b) pore widths of MCM-22, Pil-Nb-4.5, Pil$\mathrm{Nb}-10.5$ and Pil-Nb-14.8 materials and (c) micropore size distribution of Pil-Nb-4.5 in using Horwath-Kawazoe method from the Ar adsorption isotherm.

The textural properties of the pillared MWW-type materials in Table 1 show an increase in the specific surface when the $\mathrm{Nb}$ content decreases. The Pil-Nb-4.5 sample shows a specific surface of $833 \mathrm{~m}^{2} \mathrm{~g}^{-1}\left(383 \mathrm{~m}^{2} \mathrm{~g}^{-1}\right.$ more than MCM-22) and an increase in pore volume related to $\mathrm{V}_{\text {meso }}$ created by pillaring. In addition, the values of $S_{\text {ext }}$ for the Pil-Nb-4.5 sample with $727 \mathrm{~m}^{2} \mathrm{~g}^{-1}$ are six times higher than that of the MCM-22 sample and confirms that pillars separate the MWW lamellae. For the Pil-Nb-10.5, Pil-Nb-14.8 materials, the $S_{\text {ext }}$ values are three times higher than that of MCM-22. On the other hand, $\mathrm{V}_{\text {micro }}$ of Pil-Nb-10.5 and Pil-Nb-14.8 are similar to that of the MCM-22 zeolite and may indicate that the interlamellar mesoporosity was not completely maintained when concentrations of $\mathrm{Nb}$ is higher than $4.5 \%$. The low $\mathrm{V}_{\text {micro }}$ of Pil-Nb-4.5 $\left(0.03 \mathrm{~cm}^{3} \mathrm{~g}^{-1}\right)$ reveals that the portion of micropores formed in the condensation of silanol groups between MWW lamellae (the case of MCM-22) was replaced for interlamellar mesopores formed by pillaring. Furthermore, the silica could partially fills the ten-membered ring sinusoidal micropore channels in individual MWW lamellae, which also contributes to the low micropore volume. To obtain more information of the micropores in Pil-Nb-4.5, Ar adsorption isotherm was performed and the microporous size distribution (using Horwath-Kawazoe method) is shown in Figure 2c. It was observed the maximal 
distribution centred at $0.5 \mathrm{~nm}$ corresponds to 10 -membered ring sinusoidal micropore channels in the MWW lamella, which confirms the presence of micropores. Moreover, the $\mathrm{V}_{\text {micro }}$ estimated was $0.03 \mathrm{~cm}^{3} \mathrm{~g}^{-1}$, which is similar to the $\mathrm{V}_{\text {micro }}$, obtained from the $\mathrm{N}_{2}$ adsorption isotherm.

Figure 3 shows the SEM of the synthesized materials. A coin-like morphology is shown for the MCM-22 sample (Figure 3a), where $1.4 \mu \mathrm{m}$ hexagonal crystals are observed. The morphology and crystal habits are maintained for Pil-Nb-4.5, Pil-Nb-10.5, and Pil-Nb-14.8 (Figure 3 b, c and d, respectively) with aggregation in the case of Pil$\mathrm{Nb}-14.8$, which is associated with the pillaring process ${ }^{[27]}$. In addition, no bulk phases of niobium oxide are observed.
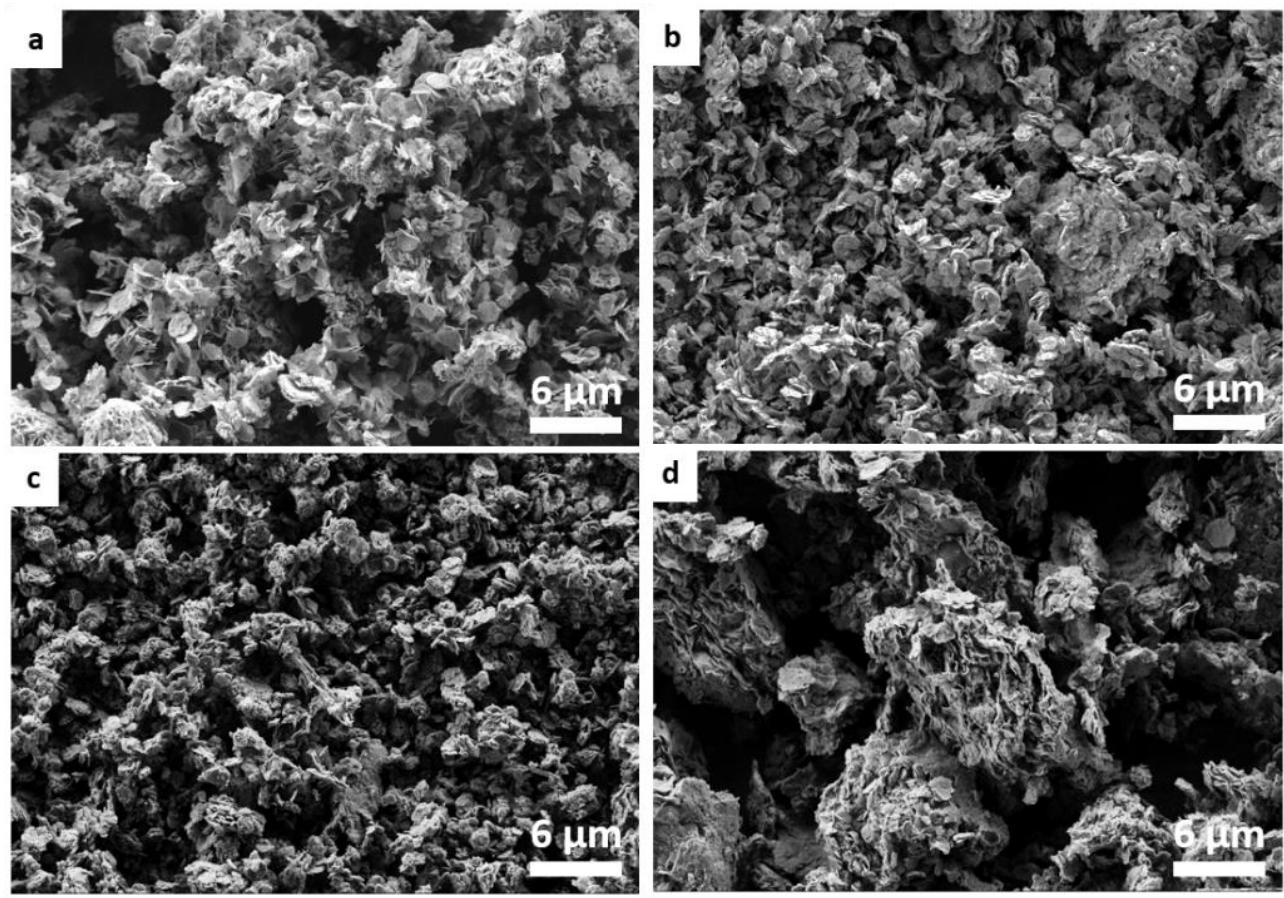

Figure 3. SEM images of (a) MCM-22, (b) Pil-Nb-4.5, (c) Pil-Nb-10.5 and (d) Pil-Nb14.8 .

TEM micrographs in the bright-field mode for the Pil-Nb-4.5 sample are shown in Figure $4 \mathrm{a}$ and the $\mathrm{d}_{100}$ spacing of $1.26 \mathrm{~nm}$ was determined by the intensity profile (see inset). This value is similar to the $\mathrm{d}_{100}$ spacing obtained by XRD (Figure 1) for the Pil$\mathrm{Nb}-4.5$ sample at $2 \theta=7.29^{\circ}(1.21 \mathrm{~nm})$, indicating that the MWW zeolitic structure is preserved. Figure $4 \mathrm{~b}$ shows six elongated individual MWW lamellae separated by approximately $2 \mathrm{~nm}$ each one, which is nearly the size of the gallery of $1.91 \mathrm{~nm}$ obtained by the XRD pattern of the Pil-Nb-4.5 sample ( $\mathrm{d}_{001}$ spacing subtracted by the thickness of individual MWW lamellae, $2.5 \mathrm{~nm}$ ). 

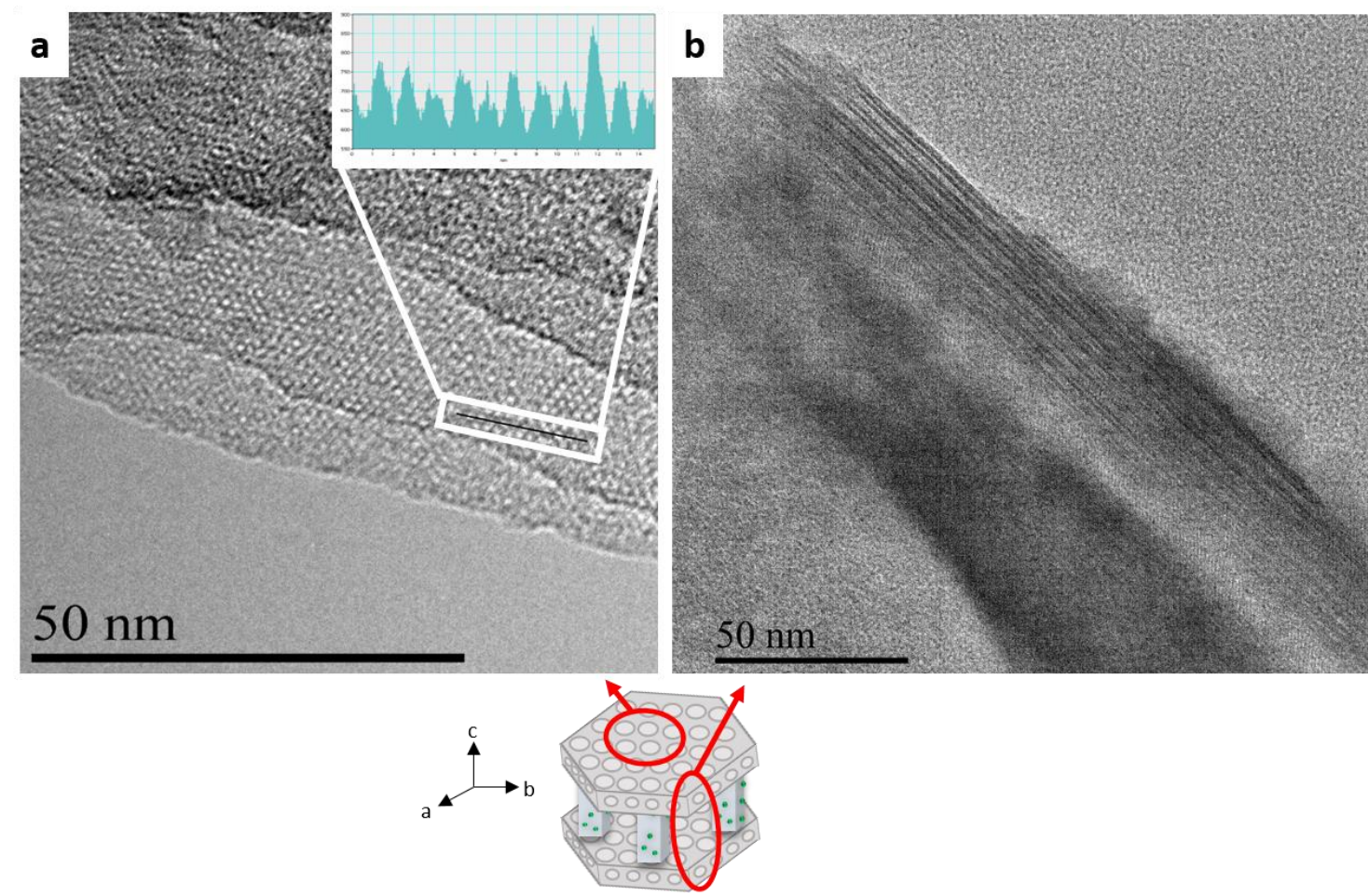

Figure 4. TEM image in BF mode of Pil-Nb-4.5 material along to the (a) $a$ plane and (b) $c$ plane.

The HAADF-STEM shown in Figure 5 examines the presence of $\mathrm{Nb}$ with singlepoint elemental analysis between individual MWW lamellae (region of pillars). Silicon $(40.56 \%)$ and oxygen (54.25\%) are the major elements, and niobium (4.36\%) is due to the pillars. No regions with a high density or bulk phases are observed in Figures 4 and 5 , confirming the good distribution of niobium and supporting his presence within the pillars.

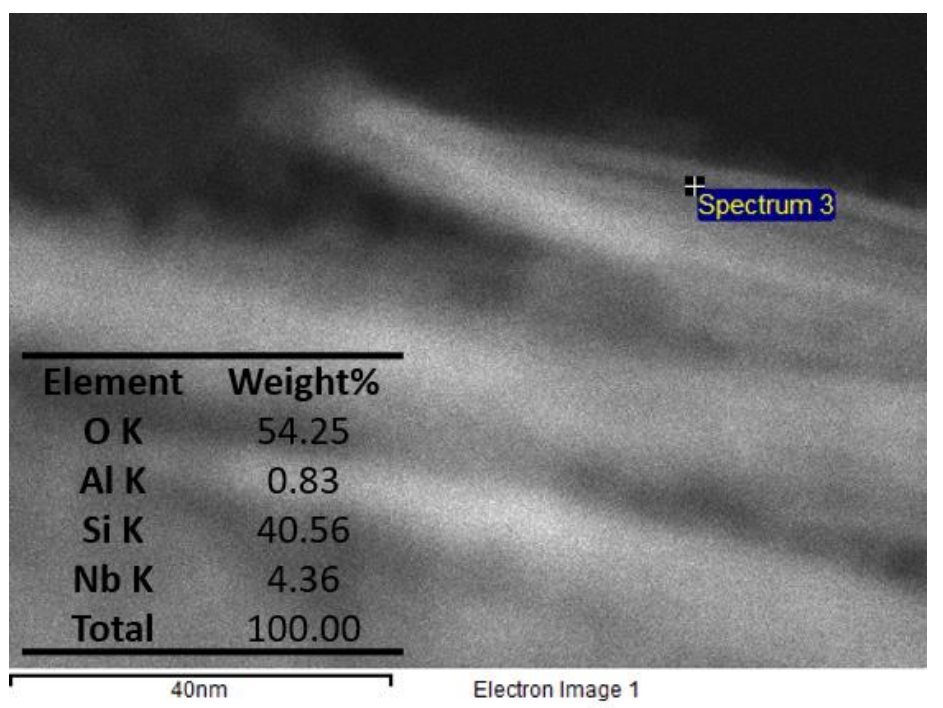

Figure 5. HAADF-STEM point elemental mapping between two MWW lamellae in the Pil-Nb-4.5 sample. 
To examine the state of $\mathrm{Nb}$ and the possibility of its extra-framework position, $\mathrm{DR}$ UV-Vis analysis of pillared samples was conducted and the results are shown in Figure 6a. All samples contain major peaks between 210 - $250 \mathrm{~nm}$ that are typical of the niobium tetrahedral coordinated species present in the framework. ${ }^{[20 a],[20 e],[28]}$ The DR UV-Vis spectrum for niobium oxide (Figure 6b) with octahedral geometry shows a characteristic band at approximately $330 \mathrm{~nm}$, which is not observed in any pillared sample.

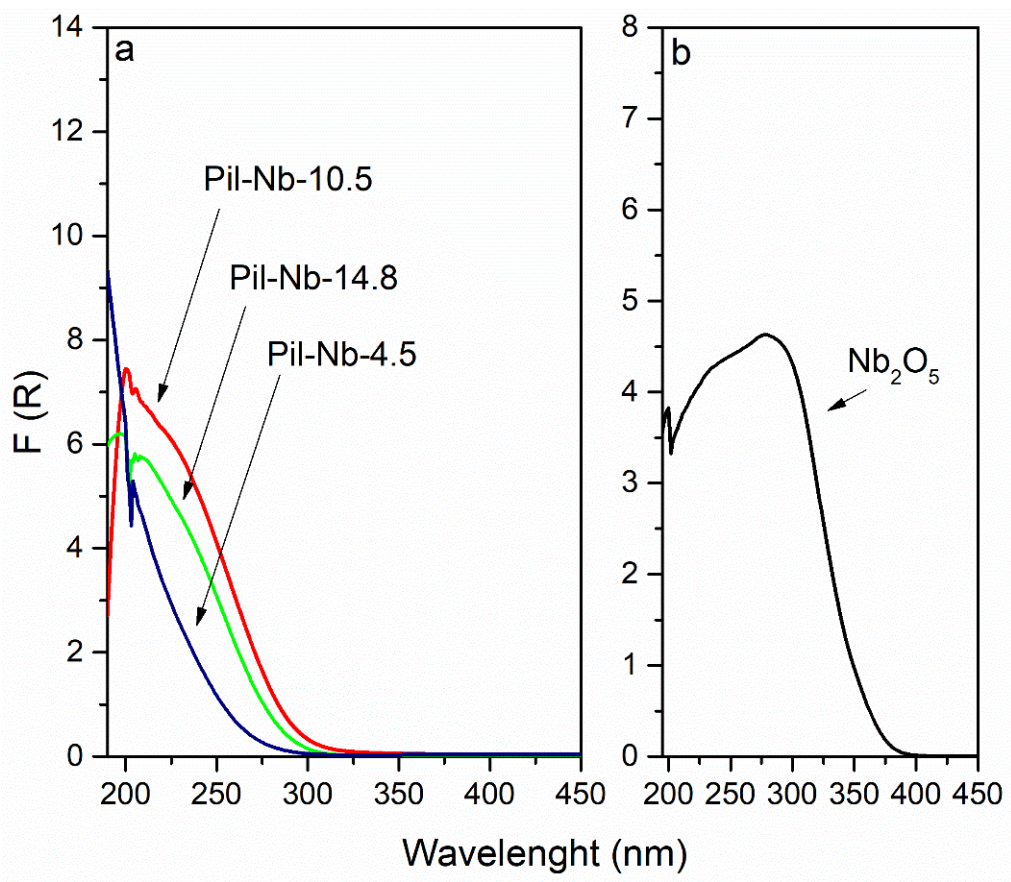

Figure 6. DR UV-Vis spectra of (a) Pil-Nb-4.5, Pil-Nb-10.5, Pil-Nb-14.8 materials and (b) niobium oxide.

Niobium species in Pil-Nb-4.5, Pil-Nb-10.5, Pil-Nb-14.8 and niobium oxide were also investigated by XPS and shown in Figure 7. The Nb3d doublet was divided into 5/2 (green lines) and 3/2 (blue lines) components and the binding energies (BE) are characteristic of $\mathrm{Nb}^{5+}$ species. The $\mathrm{BE}$ of niobium oxide appears at 207 and $210 \mathrm{eV}$ and these signals are present in Pil-Nb-4.5, Pil-Nb-10.5 and Pil-Nb-14.8 samples and are related with the extra-framework niobium oxide $\left(\mathrm{Nb}_{2} \mathrm{O}_{5}\right)$. Moreover, the signals at higher $\mathrm{BE}$ confirms niobium with distinct surroundings ( $\mathrm{NbOSi}$ ), which is also reported by other authors. ${ }^{[17,29]}$ These results may indicate that an amorphous phase of niobium is also present, which supports the absence of characteristic peaks of crystalline niobium oxide that were not detected by XRD in the pillared materials as shown in Figure 1. However, DR UV Vis spectra of pillared samples do not feature bands of niobium with octahedral geometry, which suggests that $\mathrm{Nb}_{2} \mathrm{O}_{5}$ may be present in small proportion. 
On the other hand, $\mathrm{Nb} 3 \mathrm{~d} 5 / 2$ and $\mathrm{Nb} 3 \mathrm{~d} 3 / 2$ components are observed with approximately the same BE (203 and $205 \mathrm{eV}$ ) and can be attributed to the presence of other niobium species, however, these BE display very low intensities when compared to the intensity of the $\mathrm{BE}$ above $205 \mathrm{eV}$, and may indicate the content is lower than the detection limit. According to the literature, $\mathrm{BE}$ of $203.9 \mathrm{eV}$ can be assigned to $\mathrm{NbO}\left(\mathrm{Nb}^{2+}\right)$ and the $\mathrm{BE}$ at $205.9 \mathrm{eV}$ can be assigned to $\mathrm{NbO}_{2}\left(\mathrm{Nb}^{4+}\right)$ and the surface of those species could be are oxidized predominating the presence of $\mathrm{Nb}_{2} \mathrm{O}_{5} \cdot{ }^{[30]}$ The XPS analysis of the MCM-22 sample was not performed because it does not have any BE in this region, as previous reported. ${ }^{[29,31]}$
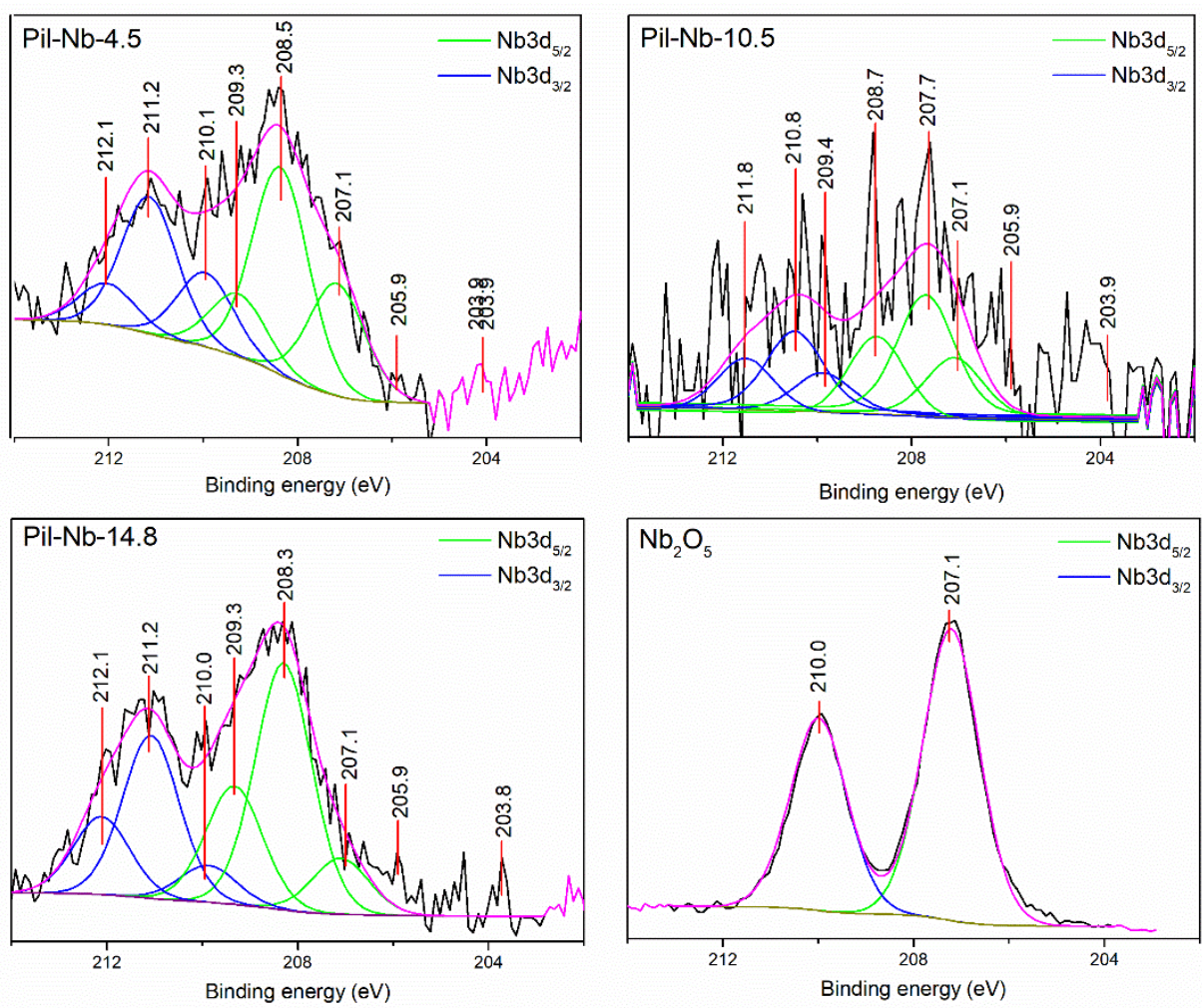

Figure 7. XPS spectra of Pil-Nb-4.5, Pil-Nb-10.5, Pil-Nb-14.8 and niobium oxide.

It has been reported that complete incorporation of niobium into silica-based materials may depend on the type of $\mathrm{Nb}$ source (oxalated, ammoniacal, chloride), $\mathrm{pH}$ and silica source. ${ }^{[3]}$ To a deeper understanding of the niobium incorporation in the pillared material, X-ray absorption spectroscopy (XAS) analysis was performed on the sample with high niobium content, Pil-Nb-14.8. XAS has become a powerful technique in all the fields of materials science and, particularly, in catalysis. The reason relies on its atomic selectivity which enables the characterization of a specific element within complex matrices composed by several chemical elements. XAS is highly sensitive to low element concentration as well, being able to measure the absorption edge of elements containing 
considerable small amounts (hundreds of ppm) respect to the total mass of the sample. In this work, XAS has been employed to obtain electronic and structural information of the $\mathrm{Nb}$ centers.

Figure 8 displays the XAS data of Pil-Nb-14.8 and respective standards. The XANES spectra Figure 8 a shows that $\mathrm{Nb}$ centers are mainly present as $\mathrm{Nb}^{5+}$ in sample Pil-Nb-14.8 once the absorption edge is positioned at the same energy as for the $\mathrm{Nb}(\mathrm{V})$ based compounds, which corroborates with XPS results. As previously reported, a change occurs in the $\mathrm{Nb}$ coordination state in supported niobia, from tetrahedral to octahedral, upon adsorption of water molecules ${ }^{[32]}$, while for dry $\mathrm{Nb}_{2} \mathrm{O}_{5}$ the weak pre-edge feature is related to distorted octahedral metal sites. In Pil-Nb-14.8, the coordination of water molecules could convert the $\mathrm{Nb}$ sites from tetrahedral to octahedral geometry, resulting in low pre-edge intensity. Notwithstanding, the local environment of $\mathrm{Nb}$ in our sample is in agreement with that ascribed for $\mathrm{Nb}$ tetrahedrally coordinated. ${ }^{[20 \mathrm{a}, 33]}$
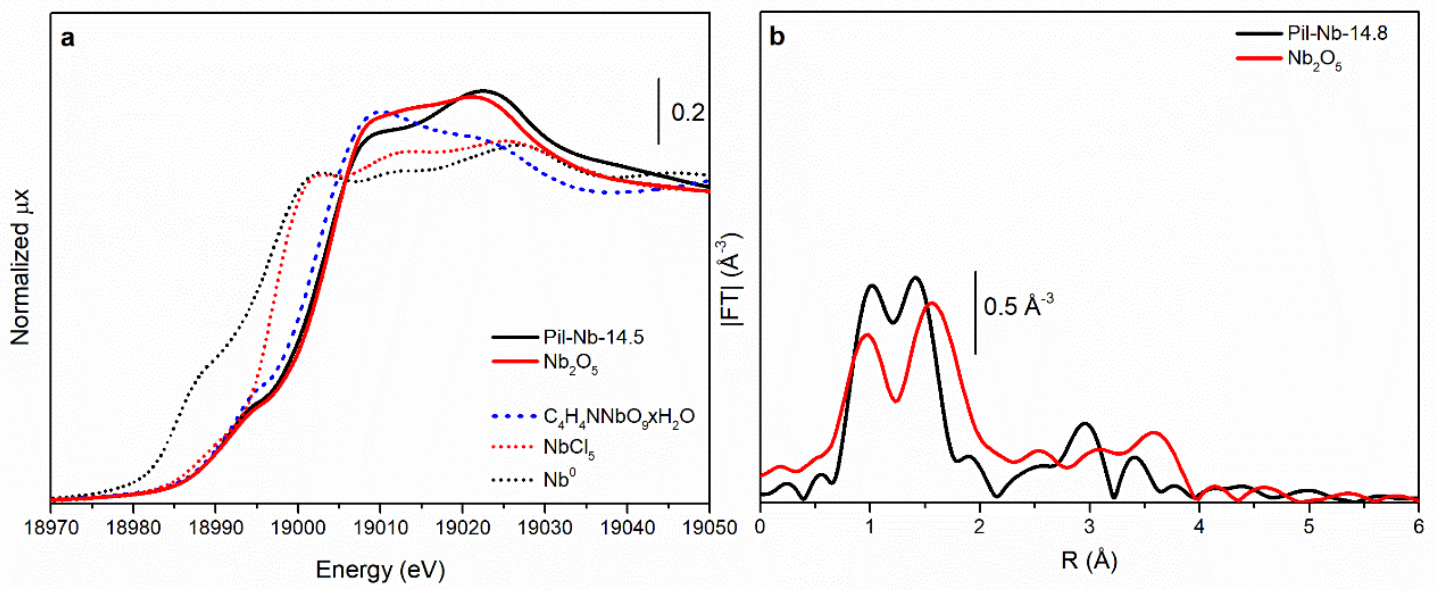

Figure 8. Normalized XANES spectra at $\mathrm{Nb}$ K-edge (a) and respective $\mathrm{k}^{2}$-weighted $|\mathrm{FT}|$ spectra (b) of Pil-Nb-14.8.

The $\mathrm{k}^{2}$-weighted $|\mathrm{FT}|$ spectra of the sample and $\mathrm{Nb}$ standards are represented in Figure $8 \mathrm{~b}$. As already commented for the XANES, the EXAFS spectra of the sample and $\mathrm{Nb}_{2} \mathrm{O}_{5}$ are rather similar, with the presence of a split first-shell related to the $\mathrm{Nb}-\mathrm{O}$ contribution. However, the position of this peak in the spectrum of $\mathrm{Nb}_{2} \mathrm{O}_{5}$ is shifted to longer R-values than that of the sample, which reinforces that $\mathrm{Nb}$ local order is different. Also, by looking at the higher shells one can notice that they are not superimposed, pointing out to a different order at higher distances. The similarities observed here could be ascribed to a certain hydration degree of the sample during XAS measurements or even to the presence of $\mathrm{Nb}_{2} \mathrm{O}_{5}$ domains in the silica-based pillars. 
The surface properties of MWW materials were characterized by FTIR spectroscopy with adsorption-desorption of pyridine as a probe molecule. Figure 9a shows the FTIR spectra in the hydroxyl region and the vibration bands centered at 3730 and $3748 \mathrm{~cm}^{-1}$, which are assigned to the internal and external silanol groups, respectively [34]. Moreover, the vibration bands at $3620 \mathrm{~cm}^{-1}$ and $3670 \mathrm{~cm}^{-1}$ correspond to surface bridged hydroxyl groups associated with framework $\mathrm{Al}-\mathrm{OH}-\mathrm{Si}$ and extra-framework aluminum species generated upon calcination, respectively ${ }^{[35]}$.
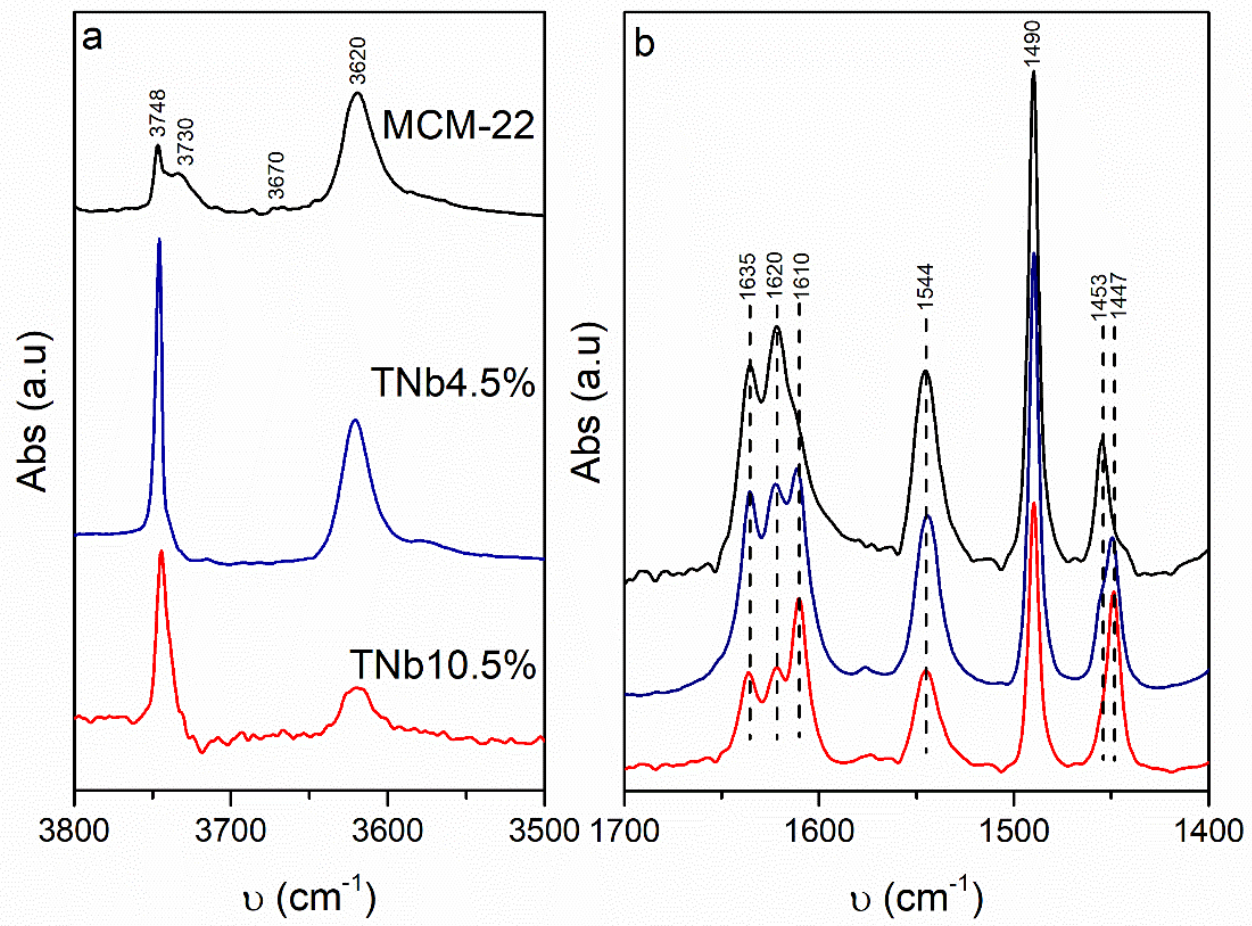

Figure 9. FTIR after outgassing at $400{ }^{\circ} \mathrm{C}$ for $2 \mathrm{~h}$ and spectra after pyridine adsorption at $150{ }^{\circ} \mathrm{C}$ for samples MCM-22, Pil-Nb-4.5 and Pil-Nb-10.5 with (a) hydroxyl group regions and BAS and (b) LAS sites. Spectra were normalized to $11.3 \mathrm{mg}$ sample.

The intensity of the band at $3748 \mathrm{~cm}^{-1}$ for the Pil-Nb-4.5 and Pil-Nb-10.5 samples is higher than that of the MCM-22 zeolite, which is associated with silanols from the pillar walls between MWW lamellae. Moreover, a smaller and wider band is observed for the sample Pil-Nb-10.5 and suggests that the increase of $\mathrm{Nb}$ content reduces the silanol groups, and consequently increases the hydrophobicity, which is beneficial for reactions where apolar reactants (as BTX) are involved. Hence, the increase of Nb content could stress the pillars between lamellae and decrease the lamellar stacking along the $c$ axis, which is also reported when $\mathrm{Zr}$ was inserted in pillared clay material. ${ }^{[36]}$ In addition, the vibration peaks centered at $3730 \mathrm{~cm}^{-1}$ are associated with surface silanol groups, which 
decrease after pillaring since $\mathrm{Si}-\mathrm{O}-\mathrm{Si}$ bonds were formed between silanol groups of the MWW lamellae and pillars upon calcination. Finally, the band at $3620 \mathrm{~cm}^{-1}$ is maintained for pillared materials and indicates that the framework of $\mathrm{Al}-\mathrm{OH}-\mathrm{Si}$ species were preserved.

Table 2. Number of BAS and LAS ( $\mu$ mol Py $\mathrm{g}^{-1}$ ) of Pil-Nb-4.5, Pil-Nb-10.5 and MCM22.

\begin{tabular}{cccccccccc}
\hline & \multicolumn{1}{c}{$\mathbf{1 5 0}^{\circ} \mathbf{C}$} & \multicolumn{3}{c}{$\mathbf{2 5 0}^{\circ} \mathbf{C}$} & \multicolumn{3}{c}{$\mathbf{3 5 0}^{\circ} \mathbf{C}$} \\
\hline Sample & BAS & LAS & Total & BAS & LAS & Total & BAS & LAS & Total \\
\hline Pil-Nb-4.5 & 51 & 23 & 74 & 45 & 11 & 56 & 39 & 11 & 50 \\
Pil-Nb-10.5 & 45 & 26 & 71 & 21 & 6 & 27 & 15 & 6 & 21 \\
MCM-22 & 54 & 18 & 72 & 48 & 15 & 63 & 36 & 15 & 51 \\
\hline
\end{tabular}

The MWW-type pillared materials show acid sites with different natures and strengths with pyridine as the adsorbed molecule in Figure $9 \mathrm{~b}$ and values in Table 2. Specifically, vibration bands at $1620-1640 \mathrm{~cm}^{-1}$ are associated with the vibration of piridinium cations. The bands at $1610 \mathrm{~cm}^{-1}\left(1453 \mathrm{~cm}^{-1}\right)$ and $1544 \mathrm{~cm}^{-1}\left(1635 \mathrm{~cm}^{-1}\right)$ are characteristics of pyridine adsorbed on Lewis (LAS) and Brønsted (BAS) acid sites, respectively, and the band at $1490 \mathrm{~cm}^{-1}$ is characteristic of pyridine adsorbed on both LAS and BAS acid sites. Furthermore, the vibration band observed at $\sim 1447 \mathrm{~cm}^{-1}$ is assigned to hydrogen-bonded species that result from the interaction of hydroxyl groups on the zeolite surface ${ }^{[34]}$. The band at $1610 \mathrm{~cm}^{-1}$ for the MCM-22, Pil-Nb-4.5 and Pil-Nb-10.5 becomes prominent and suggests the increase of LAS with the increase of $\mathrm{Nb}$ content. Hence, the signal at $\sim 1447 \mathrm{~cm}^{-1}$ is more intense for Pil-Nb-4.5 and Pil-Nb-10.5 samples, probably by the interaction of pyridine with hydroxyl groups formed after pillaring.

The intensity of the band at $1544 \mathrm{~cm}^{-1}$ decreases after pillaring, which indicates that the number of BAS was "diluted" by the insertion of silica pillars and increases with niobium content. On the other hand, LAS estimated by the signal at $1454 \mathrm{~cm}^{-1}$ increases with the increase of $\mathrm{Nb}$ content.

A schematic representation of the synthesized MWW-type materials from the MCM-22(P) sample to pillared materials with silicon and niobium oxide is shown in Figure 10. The swelling procedure is able to intercalate surfactant molecules between individual MWW lamellae, and an increase in the $\mathrm{d}_{001}$ spacing from 2.6 to $4.0 \mathrm{~nm}$ is obtained. The Swollen(P) material and a pillaring solution containing silicon and niobium alkoxides with different molar ratios are mixed. The surfactant molecules were removed by calcination with the simultaneous formation of rigid pillars of silicon and niobium 
oxide between MWW lamellae. Niobium occupying both framework (green dots) and extra-framework (blue ellipsoids) positions were present in pillared materials, according to the XPS and XAS analyses. The increase of $\mathrm{Nb}$ content (higher than $\mathrm{Nb} 4.5 \mathrm{wt} \%$ ) decreases the $\mathrm{d}_{001}$ spacing, the order of lamellar stacking and the interlamellar mesoporosity.

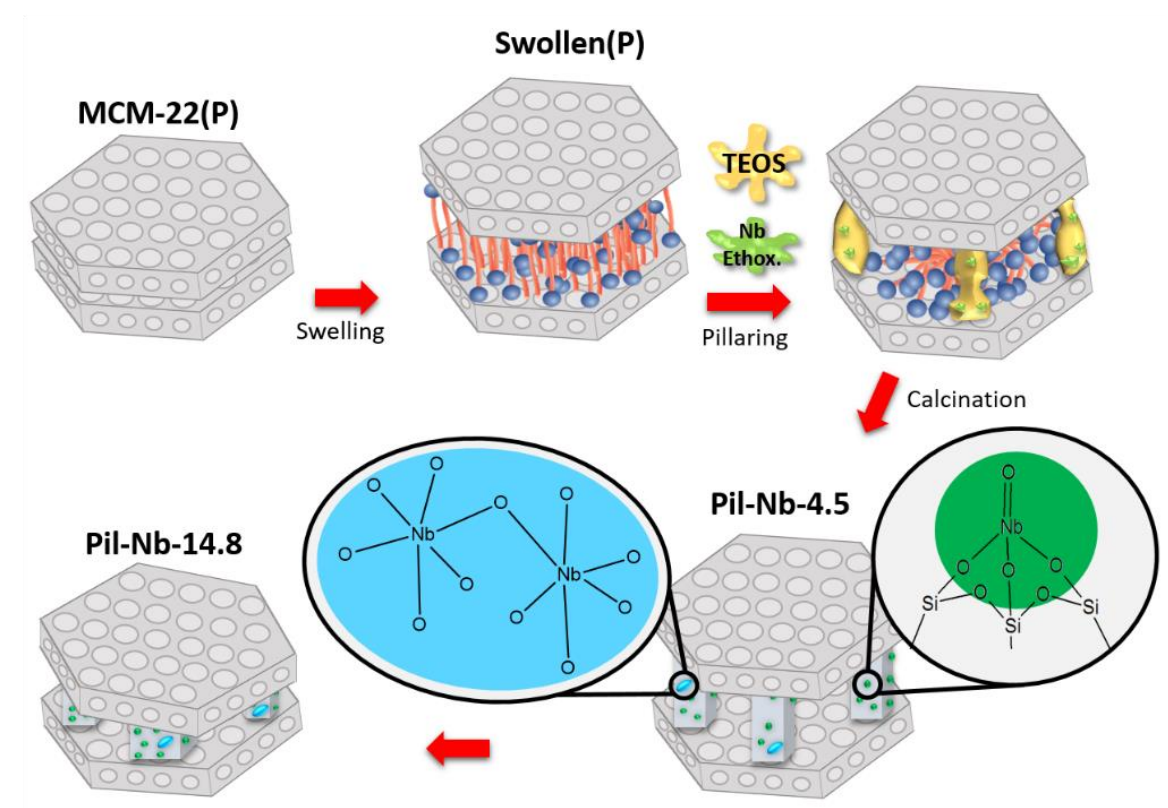

Figure 10. Schematic representation of the synthesized materials: MCM-22(P), Swollen(P), Pil-Nb-4.5 and Pil-Nb-14.8.

Figure 11 shows the conversion percentage for the oxidation of benzene, toluene, and o-xylene as a function of reaction temperature for the Pil-Nb-4.5, Pil-Nb-10.5, PilNb-14.8 and pure MCM-22 (as the catalysts for the control experiment). The inset in Figure 11 (image a) shows a scheme for the BTX oxidation reaction. We were interested in investigating how the catalytic performances of Pil-Nb-4.5, Pil-Nb-10.5 and Pil-Nb14.8 towards BTX oxidation are dependent upon their physicochemical properties. No significant conversion is detected for the pure MCM-22. To investigate the influence of the surface area and accessibility, the MWW zeolite containing only silica pillars was tested and shown similar conversions than pure MCM-22. The MWW pillared materials containing niobium show good catalytic activities at relatively low temperatures (the BTX oxidation begins just below at $50{ }^{\circ} \mathrm{C}$ ) and low metal loadings (4.5 wt \%), showing that the appropriate combination of niobium can provide higher activities related to their individual counterparts. The BTX conversion increases with temperature for all catalysts, as expected, and only $\mathrm{H}_{2} \mathrm{O}$ and $\mathrm{CO}_{2}$ are detected as reaction products. 

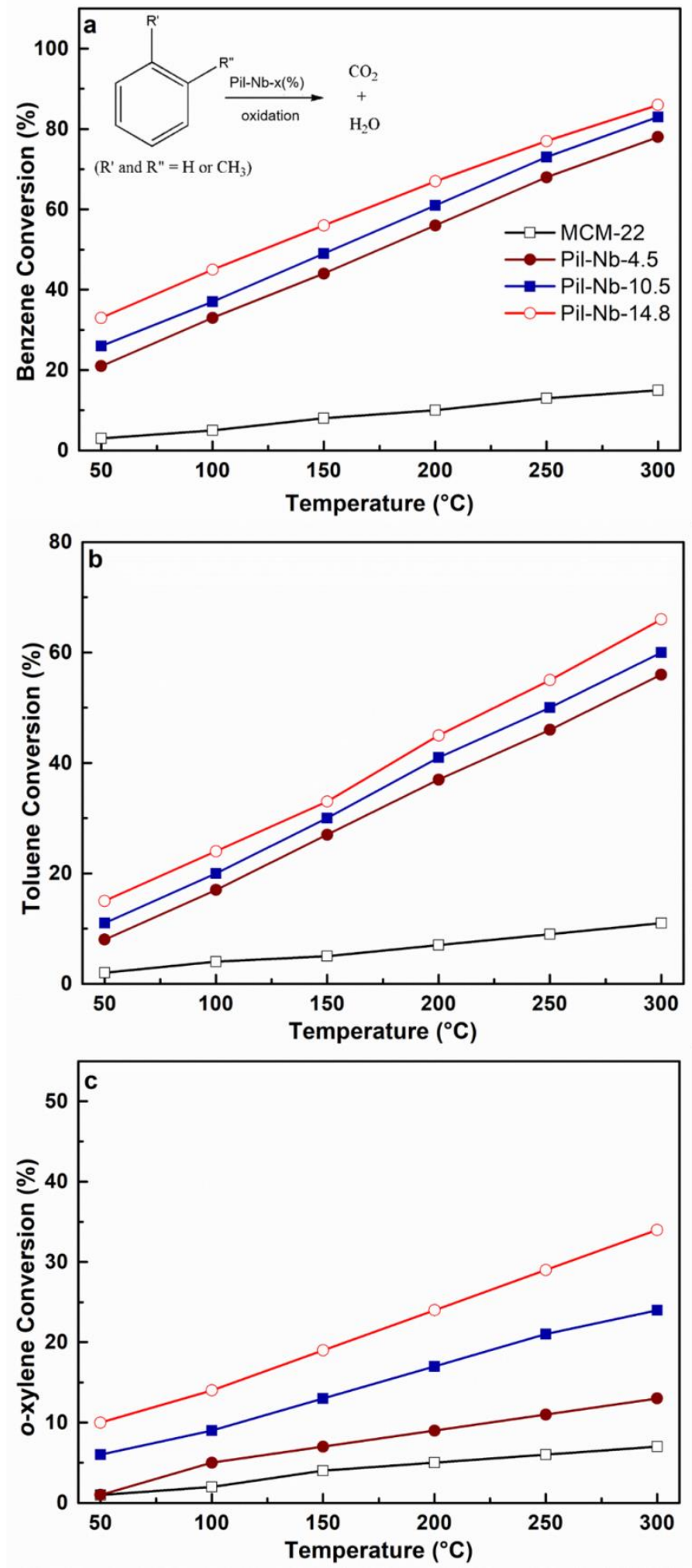

Figure 11. Catalytic oxidation of (a) benzene, (b) toluene, and (c) o-xylene as a function of temperature, catalysed by Pil-Nb-4.5, Pil-Nb-10.5, Pil-Nb-14.8 and pure MCM-22.

Figure 11 shows that the BTX conversion increases as the niobium content increases. Specifically, there are 86 and 83 and 78\% conversion for benzene; 66, 60 and $56 \%$ conversion for toluene; and 34, 24 and $13 \%$ conversion for o-xylene at $300{ }^{\circ} \mathrm{C}$ when the catalysts Pil-Nb-14.8, Pil-Nb-10.5 and Pil-Nb-4.5 are compared, respectively. 
In addition, the oxidation of organic compounds promoted by metal catalysts is recognized as a catalyst structure-sensitive reaction. ${ }^{[37]}$ Interestingly, the BTX conversion increases as the $\mathrm{V}_{\text {micro }}$ of the pillared materials remains close to the value of pure MCM22. For example, at $300{ }^{\circ} \mathrm{C}$, the conversion efficiency for benzene is $86 \%$ of that for Pil$\mathrm{Nb}-14.8\left(\mathrm{~V}_{\text {micro }}\right.$ of $\left.0.14 \mathrm{~cm}^{3} \mathrm{~g}^{-1}\right)$ but only $72 \%$ of that for Pil-Nb-4.5 with a $\mathrm{V}_{\text {micro }}$ of 0.03 $\mathrm{cm}^{3} \mathrm{~g}^{-1}$.

The pillaring procedure increases the external surface for the pillared materials, which allows the rapid diffusion of reactants and products into the active sites, confirming that the nature and structure of the pillared materials can influence their catalytic performance. Therefore, it is plausible that the diffusion of gas molecules does not prevent access to the gallery region between the lamellae, and the increase in $\mathrm{Nb}$ content between MWW lamellae could improve the catalytic activity for BTX oxidation.

Considering the catalyst with high $\mathrm{Nb}$ content (Pil-Nb-14.8\%), the increased activities can be explained by its strong niobium-support interactions and oxygen vacancy concentrations. In oxidation reactions, the catalyst is subjected to cycles of oxidation and reduction, in which both processes are affected by the oxygen mobility of the catalyst. ${ }^{[37]}$ The XPS results show the predominant presence of $\mathrm{Nb}^{5+}$ and a minority presence of $\mathrm{Nb}^{2+}$ and $\mathrm{Nb}^{4+}$.

Therefore, the mechanism for describing hydrocarbon oxidation is a redox mechanism involving the reduction of the catalyst by adsorbed hydrocarbon (benzene, toluene or xylene) with the participation of the oxygen from the lattice oxide and the formation of $\mathrm{CO}_{2}$ that is desorbed together with $\mathrm{H}_{2} \mathrm{O}$ molecules. In this case, the reduced catalyst surface $\left(\mathrm{Nb}^{4+}\right.$ or $\left.\mathrm{Nb}^{2+}\right)$ is re-oxidized $\left(\mathrm{Nb}^{5+}\right)$ by the molecular oxygen in the gasphase and this mechanism occurs via Mars-van Krevelen. ${ }^{[37-38]}$ Thus, the mechanism involves the supply of oxygen by the oxide followed by the introduction of oxygen species from the oxide into the structure of the hydrocarbon molecules and the reoxidation of the reduced solid by the oxygen-containing gas phase. In our case, the Pil-Nb-14.8 catalyst created the most active catalyst for oxidation. We believe that our results represent an important improvement in terms of performance relative to conventional systems. It is interesting to note that a slight decrease in the surface area is detected when the $\mathrm{Nb}$ content increases but this does not affect the catalytic oxidation of the BTX.

For instance, the conversion percentages are also superior to other catalysts reported in the literature, as presented in Table 3, which compares the Pil-Nb-4.5 sample fabricated here to conventional catalysts and noble metals, such as Au and Pd, supported 
in mesoporous materials under the same experimental conditions. A comparison is also made with other lamellar materials such as layered double hydroxides (LDHs) and pillared interlayered clay (PILC) previously reported as catalysts for VOCs oxidation.

Table 3. Oxidation of BTX over Pil-Nb-4.5 material and other catalysts previously reported in the literature.

\begin{tabular}{|c|c|c|c|c|c|c|c|}
\hline \multirow[b]{2}{*}{ Catalysts } & \multirow[b]{2}{*}{$\begin{array}{c}\text { Metal } \\
\text { loading } \\
(\%)\end{array}$} & \multirow[b]{2}{*}{ Substrate } & \multicolumn{4}{|c|}{ Space } & \multirow[b]{2}{*}{ Reference } \\
\hline & & & $\begin{array}{c}\text { Temp. } \\
\left({ }^{\circ} \mathbf{C}\right)\end{array}$ & $\begin{array}{c}\text { Conv. } \\
(\%)\end{array}$ & $\begin{array}{c}\text { Velocity } \\
\text { (mL.g } \\
\left.{ }^{\mathbf{1}} \cdot \mathbf{h}^{-1}\right)\end{array}$ & $\begin{array}{l}\text { TOF } \\
\left(\mathbf{h}^{-1}\right)\end{array}$ & \\
\hline Pil-Nb-4.5 & 4.5 & Benzene & 300 & 78 & 12000 & 1754 & This work \\
\hline Pil-Nb-4.5 & 4.5 & Toluene & 300 & 56 & 12000 & 693 & This work \\
\hline $\mathrm{Au} / \mathrm{MCM}-41$ & 5.0 & Benzene & 300 & 61 & 12000 & 58 & [39] \\
\hline $\mathrm{Au}-\mathrm{Pd} / \mathrm{MCM}-41$ & 5.6 & Benzene & 300 & 68 & 12000 & 52 & [39] \\
\hline $\mathrm{Cu} / \mathrm{MnO}_{x}-\mathrm{CeO}_{2}$ & 2.54 & Benzene & 270 & 50 & 30000 & 30 & [40] \\
\hline $\mathrm{Au} / \mathrm{MCM}-41$ & 5.0 & Toluene & 300 & 44 & 12000 & 32 & [39] \\
\hline $\mathrm{Au}-\mathrm{Pd} / \mathrm{MCM}-41$ & 5.6 & Toluene & 300 & 49 & 12000 & 39 & [39] \\
\hline AuCo-10 & $\begin{array}{c}8.5(\mathrm{Co} \\
)^{1.21(\mathrm{Au})}\end{array}$ & Toluene & 255 & 50 & 40000 & 660 & [41] \\
\hline $\mathrm{Au} / \mathrm{TiO}_{2}$ & 1.3 & Toluene & 375 & 50 & 35000 & 600 & [42] \\
\hline $\mathrm{Cu}_{0.5} \mathrm{Co}_{2.5} \mathrm{Al} \mathrm{LDH}$ & $0.5 / 2.5$ & Benzene & 250 & 50 & 60000 & 60000 & [43] \\
\hline $\mathrm{Cu}_{3} \mathrm{Al}-\mathrm{MMO} \mathrm{LDH}$ & 3.0 & Benzene & 290 & 10 & 60000 & 60000 & [43] \\
\hline $\mathrm{CoAlONH}_{4} \mathrm{LDH}$ & $*$ & Benzene & 260 & 99 & 60000 & 60000 & [44] \\
\hline $\mathrm{CoAlONH}_{4} \mathrm{LDH}$ & $*$ & Toluene & 250 & 99 & 60000 & 60000 & [44] \\
\hline $\operatorname{MnCe}(6: 1) / A l-P I L C$ & $6: 1$ & Benzene & 300 & 60 & 20000 & 20000 & [45] \\
\hline
\end{tabular}

LDH: Layered Double Hydroxide; ${ }^{*}$ Hierarchical CoII $_{2.8}$ CoIII $_{1}$ LDH; PILC: Al-Pillared Interlayered Clay.

The remarkable catalytic activities observed for the Pil-Nb-4.5, Pil-Nb-10.5 and Pil-Nb-14.8 samples are related to four main factors. (1) The unusual surface morphology allows the production of materials with a high surface area by the separation of the MWW lamellae by pillars that increase in the external surface; this is reflected by the excellent performance for various catalytic processes related to the MWW-type zeolite counterparts. (2) The difference in the electronic structure is important because it allows different redox ratios on the surface, which are catalytically active sites for oxidation reactions. (3) The uniform distribution of niobium without significant agglomeration is 
important; a uniform distribution is often crucial for catalytic activities and the presence of $\mathrm{Nb}^{2+}, \mathrm{Nb}^{4+}$ and $\mathrm{Nb}^{5+}$ on the surface of the catalyst provides very catalytically active sites for the oxidation reaction. (4) The presence of Lewis acid sites provided by the introduction of niobium, which is characterized by FTIR spectroscopy with pyridine as the probe molecule (Figure 9).

We believe that the niobium metal centers act as Lewis acid sites on the surface of the catalyst, which should be an additional stabilizing effect of the adsorbed species. The presence of Lewis acid sites present in the catalyst may allow the substrate molecules to interact with the acid sites of the catalyst and electrostatically activate the methyl group in order to the oxidation reaction occurs. The remarkable catalyst activity, stability and low $\mathrm{Nb}$ loading described herein along with the application of green chemistry principles enables the design of safer materials.

We also investigated the catalytic stability of the Pil-Nb-4.5, Pil-Nb-10.5 and Pil$\mathrm{Nb}$-14.8 materials, increasing the time of the reaction for the benzene oxidation that showed the highest activity (Figure 12). These experiments confirmed that no significant loss of catalytic activity is detected even after $36 \mathrm{~h}$, showing that these materials may represent good candidates for gas-phase catalytic applications.

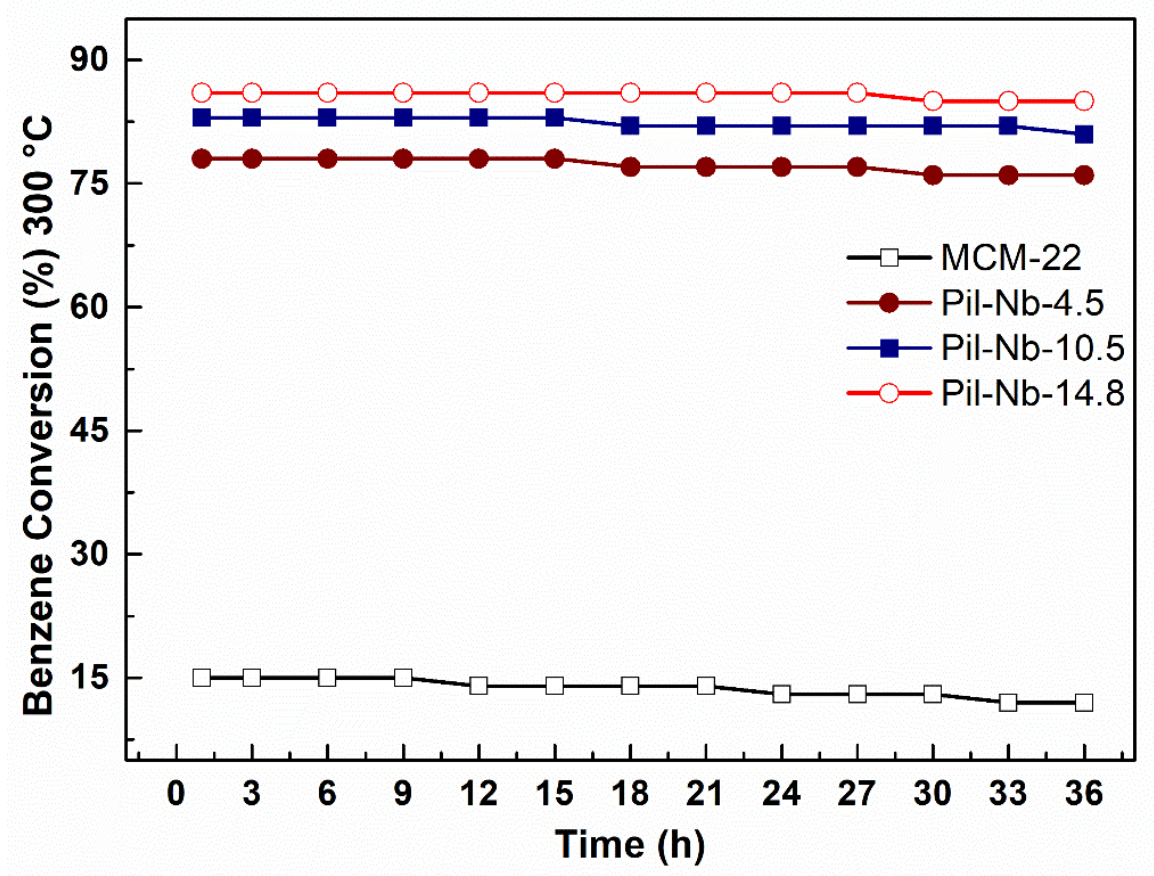

Figure 12. Benzene conversion percentages as a function of time with Pil-Nb-4.5, Pil-Nb-10.5, Pil-Nb-14.8 and MCM-22 zeolite.

Regarding the operational conditions of the reaction (gas flow rate, type of reactor, the composition of the reaction mixture) and the type of structure of the hydrocarbon, 
they can reflect directly on the oxidation BTX. Moreover, most reported catalysts are combined with other very active phases, such as noble metals or metal oxides $(\mathrm{Au}, \mathrm{Pd}$, $\mathrm{Pt}, \mathrm{Co}, \mathrm{Mn}) .{ }^{[46]}$ In our work, a hierarchical MWW zeolite with a lamellar structure containing pillars of silicon (an inert phase) and niobium oxide was studied to focus on the contribution of the niobium, which presents a very high activity. It is interesting to note that the conversion of benzene and toluene by Pil-Nb-4.5 was higher than that of $\mathrm{Au}-$ based catalysts. These results indicate that MWW-type zeolites containing pillars with silicon and niobium oxide can be considered promising catalysts for BTX oxidation.

\section{CONCLUSION}

It was possible to obtain hierarchical MWW zeolites with combined micro and mesoporous architectures where niobium participates as active species in pillars. The niobium content reveals a profound impact on the physical and chemical properties, resulting in a gradual decrease to the basal spacing and, consequently, the interlamellar mesoporosity at concentrations high than $4.5 \% \mathrm{Nb}$. However, even with the highest concentration of $14.8 \%$ niobium, the robustness of pillars still preventing the structural interlamellar collapse. The set of spectrometric analyses reveals different niobium environments, a result of the difference of the electronic structure which allows different redox ratios on the surface, which played a key role in catalytic performance. The higher catalytic activity occurred with pillared material with the high niobium content (Pil-Nb14.8), with conversions of benzene, toluene, and o-xylene of 86,66 and $34 \%$ respectively. This indicates that the diffusion of reagents and products to the active sites located on the pillars was not limited even with the reduction of interlamellar mesoporosity. All pillared materials exhibited high stability with no significant loss of activity occurred even after $36 \mathrm{~h}$ of reaction. Therefore, the present results may have important implications for the design and synthesis niobium-containing MWW-type materials with pillars as active species and excellent performance for catalytic oxidation of VOCs, and possibly many other industrially relevant oxidation reactions.

\section{ACKNOWLEDGMENTS}

A.J.S. thanks the Cordenação de Aperfeiçoamento de Pessoal de Nível Superior Brasil (CAPES) - Finance Code 001, the PDSE program (process number 99999.004779/2014-02) and the prof. Claudio Radtke from the PPGQ-UFRGS for the 
XPS analyses. C.W.L. is grateful to INOMAT/CAPES for a postdoctoral fellowship. U.D. thanks the funding by the Spanish Government (MAT2017-82288-C2-1-P).

\section{REFERENCES:}

[1] M. Misono in Chapter 1 - Basis of Heterogeneous Catalysis, Vol. Volume 176 (Ed. M. Makoto), Elsevier, 2013, pp. 1-23.

[2] a) X. Zhang, J. Guo, P. Guan, C. Liu, H. Huang, F. Xue, X. Dong, S. J. Pennycook and M. F. Chisholm, Nature Communications 2013, 4, 1924; b) W. Yan, G. Zhang, H. Yan, Y. Liu, X. Chen, X. Feng, X. Jin and C. Yang, ACS Sustainable Chemistry \& Engineering 2018, 6, 4423-4452; c) H. Sasai and S. Takizawa in Chapter 9 Vanadium-and Niobium-catalysed Enantioselective Reactions, The Royal Society of Chemistry, 2016, pp. 216-249.

[3] M. Ziolek and I. Sobczak, Catal. Today 2017, 285, 211-225.

[4] a) K. Tanabe, Catal. Today 2003, 78, 65-77; b) K. Nakajima, Y. Baba, R. Noma, M. Kitano, J. N. Kondo, S. Hayashi and M. Hara, JACS 2011, 133, 4224-4227.

[5] I. Nowak and M. Ziolek, Chem. Rev. 1999, 99, 3603-3624.

[6] a) M. E. Davis, Nature 2002, 417, 813-821; b) K. Li, J. Valla and J. Garcia-Martinez, ChemCatChem 2014, 6, 46-66; c) J. Perez-Ramirez, C. H. Christensen, K. Egeblad, C. H. Christensen and J. C. Groen, Chem. Soc. Rev. 2008, 37, 2530-2542; d) W. Schwieger, A. G. Machoke, T. Weissenberger, A. Inayat, T. Selvam, M. Klumpp and A. Inayat, Chem. Soc. Rev. 2016, 45, 3353-3376.

[7] J. Přech, P. Pizarro, D. P. Serrano and J. Čejka, Chem. Soc. Rev. 2018, 47, 8263-8306.

[8] F. S. O. Ramos, M. K. d. Pietre and H. O. Pastore, RSC Advances 2013, 3, 2084-2111.

[9] W. J. Roth, C. T. Kresge, J. C. Vartuli, M. E. Leonowicz, A. S. Fung and S. B. McCullen in MCM36: The first pillared molecular sieve with zeolite properties, Vol. Volume 94 Eds.: H. G. K. I. K. H.K. Beyer and J. B. Nagy), Elsevier, 1995, pp. 301-308.

[10] M. E. Leonowicz, J. A. Lawton, S. L. Lawton and M. K. Rubin, Science 1994, 264, 1910-1913. [11] a) S. Maheshwari, C. Martínez, M. Teresa Portilla, F. J. Llopis, A. Corma and M. Tsapatsis, J. Catal. 2010, 272, 298-308; b) E. Dumitriu, F. Secundo, J. Patarin and I. Fechete, J. Mol. Catal. B: Enzym. 2003, 22, 119-133.

[12] a) S.-Y. Kim, H.-J. Ban and W.-S. Ahn, Catal. Lett. 2007, 113, 160-164; b) A. Corma, V. Fornés, A. Chica and U. Diaz, EP Spanish Patent 9802283

1999; c) W. J. Roth and C. T. Kresge, Microporous Mesoporous Mater. 2011, 144, 158-161; d) K. $\mathrm{Na}$, M. Choi, W. Park, Y. Sakamoto, O. Terasaki and R. Ryoo, JACS 2010, 132, 4169-4177; e) K. Kosuge and A. Tsunashima, J. Chem. Soc., Chem. Commun. 1995, 2427-2428; f) P. Chlubná, W. J. Roth, H. F. Greer, W. Zhou, O. Shvets, A. Zukal, J. Čejka and R. E. Morris, Chem. Mater. 2013, 25, 542-547; g) J. Přech and J. Čejka, Catal. Today 2016, 277, 2-8.

[13] W. J. Roth, J. C. Vartuli and C. T. Kresge in Characterization of mesoporous molecular sieves: differences between M41s and pillared layered zeolites, Vol. Volume 129 Eds.: S. Abdelhamid and J. Mietek), Elsevier, 2000, pp. 501-508.

[14] W. J. Roth, P. Nachtigall, R. E. Morris and J. Čejka, Chem. Rev. 2014, 114, 4807-4837.

[15] a) J.-O. Barth, J. Kornatowski and J. A. Lercher*, J. Mater. Chem. 2002, 12, 369-373; b) J.-O. Barth, A. Jentys, E. F. Iliopoulou, I. A. Vasalos and J. A. Lercher, J. Catal. 2004, 227, 117-129.

[16] F. Jin, S. Huang, S. Cheng, Y. Wu, C.-C. Chang and Y.-W. Huang, Catalysis Science \& Technology 2015, 5, 3007-3016.

[17] A. Wojtaszek-Gurdak, M. Zielinska and M. Ziolek, Catal. Today 2019, 325, 89-97.

[18] J. Přech, P. Eliášová, D. Aldhayan and M. Kubů, Catal. Today 2015, 243, 134-140.

[19] a) T. Ushikubo, Catal. Today 2000, 57, 331-338; b) G. Sberveglieri, V. Ferrari, A. Bertuna, E. Comini, N. Poli, D. Zappa and G. Sberveglieri, Procedia Engineering 2014, 87, 807-810; c) G. Zhen, 
V. Eggli, J. Vörös, P. Zammaretti, M. Textor, R. Glockshuber and E. Kuennemann, Langmuir 2004, 20, 10464-10473.

[20] a) A. Corma, F. X. Llabrés i Xamena, C. Prestipino, M. Renz and S. Valencia, The Journal of Physical Chemistry C 2009, 113, 11306-11315; b) M. Trejda, A. Wojtaszek, A. Floch, R. Wojcieszak, E. M. Gaigneaux and M. Ziolek, Catal. Today 2010, 158, 170-177; c) A. Wojtaszek, M. Ziolek, S. Dzwigaj and F. Tielens, Chem. Phys. Lett. 2011, 514, 70-73; d) M. Hartmann, A. M. Prakash and L. Kevan, Catal. Today 2003, 78, 467-475; e) F. Tielens, T. Shishido and S. Dzwigaj, The Journal of Physical Chemistry C 2010, 114, 3140-3147; f) I. Sobczak, N. Kieronczyk, M. Trejda and M. Ziolek, Catal. Today 2008, 139, 188-195; g) M. Trejda, A. Tuel, J. Kujawa, B. Kilos and M. Ziolek, Microporous Mesoporous Mater. 2008, 110, 271-278; h) B. Kilos, A. Tuel, M. Ziolek and J.-C. Volta, Catal. Today 2006, 118, 416-424; i) A. S. Dias, S. Lima, D. Carriazo, V. Rives, M. Pillinger and A. A. Valente, J. Catal. 2006, 244, 230-237; j) A. M. Prakash and L. Kevan, JACS 1998, 120, 13148-13155.

[21] A. G. M. da Silva, T. S. Rodrigues, E. G. Candido, I. C. de Freitas, A. H. M. da Silva, H. V. Fajardo, R. Balzer, J. F. Gomes, J. M. Assaf, D. C. de Oliveira, N. Oger, S. Paul, R. Wojcieszak and P. H. C. Camargo, Journal of Colloid and Interface Science 2018, 530, 282-291.

[22] R. Balzer, L. F. D. Probst, H. V. Fajardo, F. S. Teodoro, L. V. A. Gurgel and L. F. Gil, Industrial Crops and Products 2017, 97, 649-652.

[23] C. A. Emeis, J. Catal. 1993, 141, 347-354.

[24] B. Ravel and M. Newville, J Synchrotron Radiat 2005, 12, 537-541.

[25] U. Diaz and A. Corma, Dalton Transactions 2014, 43, 10292-10316.

[26] M. V. Rodrigues, C. Okolie, C. Sievers and L. Martins, Crystal Growth \& Design 2019, 19, 231 241.

[27] P. Chlubná, W. J. Roth, A. Zukal, M. Kubů and J. Pavlatová, Catal. Today 2012, 179, 35-42.

[28] A. Ramanathan, R. Maheswari and B. Subramaniam, Top. Catal. 2015, 58, 314-324.

[29] A. Wojtaszek-Gurdak and M. Ziolek, RSC Advances 2015, 5, 22326-22333.

[30] a) M. K. Bahl, J. Phys. Chem. Solids 1975, 36, 485-491; b) S. L. Fernandes, L. G. S. Albano, L. J. Affonço, J. H. D. d. Silva, E. Longo and C. F. d. O. Graeff, Frontiers in Chemistry 2019, 7.

[31] K. Jin, T. Zhang, J. Ji, M. Zhang, Y. Zhang and S. Tang, Ind. Eng. Chem. Res. 2015, 54, 164-170. [32] H. Yoshida, T. Tanaka, T. Yoshida, T. Funabiki and S. Yoshida, Catal. Today 1996, 28, 79-89.

[33] C. Tiozzo, C. Bisio, F. Carniato, A. Gallo, S. L. Scott, R. Psaro and M. Guidotti, PCCP 2013, 15, 13354-13362.

[34] P. Matias, J. M. Lopes, S. Laforge, P. Magnoux, P. A. Russo, M. M. L. Ribeiro Carrott, M. Guisnet and F. Ramôa Ribeiro, J. Catal. 2008, 259, 190-202.

[35] S. Laforge, P. Ayrault, D. Martin and M. Guisnet, Applied Catalysis A: General 2005, 279, 7988.

[36] J. A. Cecilia, C. García-Sancho and F. Franco, Microporous Mesoporous Mater. 2013, 176, 95-102.

[37] a) M. Nolan, S. C. Parker and G. W. Watson, Surface Science 2005, 595, 223-232; b) O. H. Laguna, A. Pérez, M. A. Centeno and J. A. Odriozola, Applied Catalysis B: Environmental 2015, 176-177, 385-395.

[38] N. Guillén-Hurtado, A. García-García and A. Bueno-López, Journal of Catalysis 2013, 299, 181-187.

[39] A. G. M. da Silva, H. V. Fajardo, R. Balzer, L. F. D. Probst, A. S. P. Lovón, J. J. Lovón-Quintana, G. P. Valença, W. H. Schreine and P. A. Robles-Dutenhefner, Journal of Power Sources 2015, 285 , 460-468.

[40] X. Tang, Y. Xu and W. Shen, Chemical Engineering Journal 2008, 144, 175-180.

[41] B. Solsona, M. Pérez-Cabero, I. Vázquez, A. Dejoz, T. García, J. Álvarez-Rodríguez, J. ElHaskouri, D. Beltrán and P. Amorós, Chemical Engineering Journal 2012, 187, 391-400.

[42] M. Ousmane, L. F. Liotta, G. D. Carlo, G. Pantaleo, A. M. Venezia, G. Deganello, L. Retailleau, A. Boreave and A. Giroir-Fendler, Applied Catalysis B: Environmental 2011, 101, 629-637.

[43] S. Li, H. Wang, W. Li, X. Wu, W. Tang and Y. Chen, Applied Catalysis B: Environmental 2015, 166-167, 260-269. 
[44] S. Mo, S. Li, J. Li, Y. Deng, S. Peng, J. Chen and Y. Chen, Nanoscale 2016, 8, 15763-15773. [45] S. Zuo, Q. Huang, J. Li and R. Zhou, Applied Catalysis B: Environmental 2009, 91, 204-209. [46] a) J. M. López, A. L. Gilbank, T. García, B. Solsona, S. Agouram and L. Torrente-Murciano, Applied Catalysis B: Environmental 2015, 174-175, 403-412; b) M. Hatanaka, N. Takahashi, T. Tanabe, Y. Nagai, K. Dohmae, Y. Aoki, T. Yoshida and H. Shinjoh, Applied Catalysis B: Environmental 2010, 99, 336-342; C) W. B. Li, J. X. Wang and H. Gong, Catalysis Today 2009, 148, 81-87. 